\title{
Effects of Ethanol Contamination on Friction and Elastohydrodynamic Film Thickness of Engine Oils
}

\section{Henara L. Costa}

Laboratorio de Tribologia e Materiais, Universidade Federal de Uberlandia, Uberlandia, Brazil

\section{Hugh Spikes}

Tribology Group, Department of Mechanical Engineering , Imperial College London ,

London, UK

\begin{abstract}
The use of ethanol as engine fuel has increased for environmental reasons, both in flex-fuel engines, and as increasing amounts of ethanol blended with gasoline in conventional engines. This paper describes an investigation into the effects of ethanol contamination of lubricants during engine use with ethanol fuel. To facilitate this, a new technique was developed to measure small amounts of ethanol in lubricants. Elastohydrodynamic film thickness measurements and Stribeck curves were obtained for Group I base and formulated oils containing small added amounts of ethanol. The effect of the water present in hydrated ethanol was evaluated by carrying out tests using both
\end{abstract}


hydrated and anhydrous ethanol. Measurements were also carried out using a Group II base oil with added ethanol. These measurements showed that in the low entrainment speed region, where the elastohydrodynamic film is very thin so that boundary lubrication prevails, the addition of ethanol produced a boundary film, which was not present for the base oils. By contrast the addition of ethanol to formulated oil reduced film thickness in all lubrication regimes. The friction tests showed friction reduction due to addition of ethanol to the base oil, in particular at low speeds. For the formulated oil, ethanol reduced friction at high speeds, which was associated with a reduction in the viscosity of the lubricant, but at low speeds, ethanol reduced the formation of a boundary layer, increasing friction. The presence of water in hydrated ethanol did not change significantly film thickness and friction when compared with anhydrous ethanol.

Keywords: ethanol, fuel dilution, lubricant, engine oil, film thickness, ultrathin interferometry, Stribeck curves

\section{INTRODUCTION}

Ethanol is being increasingly used as an alternative fuel to petroleum-based gasoline and diesel derivatives, driven by the potentially damaging effect of global warming and depletion in the supply of fossil fuels ( $\mathrm{Wu}$, et al. (1)). The addition of ethanol to gasoline fuel started in many countries around 1930, but was greatly increased during the petroleum crisis in the 1970s.

In Brazil, a governmental ethanol programme launched in 1975 aimed to implement national technologies both for ethanol production from sugar cane and adaptation of car 
engines for use with ethanol fuel (Bastian-Pinto, et al. (2)). The production of ethanolfuelled automobiles started in 1981 in Brazil, which was the global pioneer in promoting ethanol at large-scale as a vehicle fuel, and is today the second largest world producer of ethanol (Cavalcanti, et al. (3)). In the 1990s, facing the difficulties of reliable ethanol supply throughout the year, the Brazilian automobile industry decided to develop a mixed fuel engine which could run on any proportion of ethanol and gasoline, now known as the flex-fuel engine. This fuel flexibility is possible due to an electronic system that uses the lambda probe signal to monitor the composition of exhaust gases in order to identify the fuel present in the tank and thereby choose the fuel mixture (Ahn, et al. (4)). This tank fuel varies from $22 \%$ of anhydrous ethanol (99.5\% of pure ethanol and $0.5 \%$ water), which is the amount of ethanol normally added to gasoline according to Brazilian legislation, to pure hydrated ethanol, containing $93 \%$ of ethanol and $7 \%$ of water. Nowadays half of the amount of combustible used in Brazilian automobiles is renewable (Cavalcanti, et al. (3)) and according to the national association of automotive vehicle manufacturers (Anfavea), flex-fuel engines account for $88 \%$ of the vehicles produced in Brazil. In the United Sates, an Act of 1988 stimulated the development of bi-fuel vehicles, which use a fuel known as E85, indicating a mixture of $85 \%$ ethanol and 15\% gasoline (Bastian-Pinto, et al. (2)). This limit was set to avoid engine cold start problems in the extreme weather conditions that may occur in temperate countries. To meet this demand, the volume of ethanol produced in the US increased 22-fold between 1980 and 2005 (Dutcher, et al. (5)). In Europe, the directive (2003/30/EC (6)) aimed to introduce biofuels in transport, and in 2009 the directive (2009/28/EC (7)) established a target of $10 \%$ of renewable fuels in transport by 
2020. Many countries, such as Sweden (Linde (8)) and Belgium (Pelkmans, et al. (9)), have been adopting policies that involve an increased use of biofuels to reach this 10\% target.

As well as reducing dependence on oil supplies, the use of ethanol fuel can offer further advantages. When the complete cycle is taken into account, from fuel production to use in vehicles, $\mathrm{CO}_{2}$ emissions are reduced compared to gasoline (Dutcher, et al. (5)). Also, the addition of ethanol to a fuel reduces the particulate mass concentration in the exhaust (Dutcher, et al. (5, Maricq (10)). For example, it has been found that compared with pure gasoline, the use of E85 reduces semivolatile organic formation by 4 to 7 times and the soot agglomerates reduce in size to less than half (Maricq (10)).

However, the use of ethanol as fuel poses some tribological issues due to the possibility of contamination of the lubricant with ethanol. Incorporation and dilution of ethanol in the lubricant is particularly likely during engine cold start (Boons, et al. (11, Chui, et al. (12)). Tribological challenges in automotive engines seem to be related to inadequate lubrication and tribochemical wear (Ferrarese, et al. (13, De Silva, et al. (14, De Silva, et al. (15)). Severe wear has been frequently reported by users of various sizes and models of flex-fuel engines and components particularly affected are piston rings (Ferrarese, et al. (13)), valves and valve lifters (Ferrarese, et al. (13, Volcci (16)). Despite this challenge, very few studies on the effects of ethanol on friction (De Silva, et al. (14, De Silva, et al. (15)), lubrication (Chui, et al. (12, Boons, et al. (17, Chui and Millard (18)) and wear (Ferrarese, et al. (13, Volcci (16)) of automotive engine parts can be found in the literature.

This paper aims to investigate to which extent the tribological problems frequently reported for flex-fuel engines are related to the effects of ethanol on film formation and friction. To 
do this, elastohydrodynamic (EHL) film thicknesses were measured for lubricants contaminated with ethanol over a wide range of speeds, to span lubrication regimes ranging from boundary to EHL. These results were complemented with measurement of Stribeck curves, to help understand the mechanisms by which the presence of ethanol can affect friction. In order to separate the interaction of ethanol with the base oil from that with other additives, both base oils and formulated oils without friction modifiers were investigated.

\section{BACKGROUND}

Since ethanol has a much higher latent heat of evaporation than gasoline, accumulation of ethanol in the lubricant can be significant, particularly in cold-start/warm-up/short-trip conditions (De Silva, et al. (15)). ASTM V-D oil sequence tests using neat ethanol have shown ethanol accumulation in the sump of $25 \%$ (Chui, et al. (12)) while field tests using E85 under conditions that lead to low lubricant temperatures have shown around 6\% ethanol accumulation (Boons, et al. (11)).

Since this ethanol accumulation is expected to influence lubrication and therefore friction, De Silva et al. used a Plint TE77 reciprocating tribometer to investigate friction at the piston ring/cylinder wall interface for a fully formulated gasoline engine lubricant contaminated with ethanol and water (De Silva, et al. (15)). They found that although the presence of ethanol did not affect friction measurements significantly, the combined presence of water and ethanol in the lubricant reduced friction. They also measured friction using the phases separated from a contaminated lubricant when left undisturbed, as would happen when a vehicle is parked or garaged (De Silva, et al. (14)), and found friction 
reduction when the contact was lubricated with the separated oil and the sludge phases of the lubricant/ethanol/water mixtures compared to the formulated reference lubricant.

However, a more fundamental investigation of the effects of the contamination of lubricants with ethanol on the tribological performance of automotive parts is still necessary. Engine lubricants are composed of a base fluid and various dissolved additives. The base fluid determines the blend's physical properties, such as rheology, volatility and solvency, while the additives improve specific aspects, mainly chemical, of the lubricant performance. It is possible that ethanol may influence lubrication due to its interaction with the base oil or with the additives such as the friction modifier, the anti-wear additive and the detergent.

One possibility is the fractionation of the ethanol diluted in the lubricant close to the moving surfaces. A substance that is more polar than the base fluid such as ethanol can be preferentially attracted to the lubricated surface by van der Waals forces. Therefore, a very thin layer mainly composed of the more polar component in the base oil + ethanol mixture may form very close to the surface, changing the near-surface viscosity. Guangteng and Spikes ((19)) have demonstrated the impact of molecular fractionation of base fluid mixtures on metal surfaces using ultrathin film interferometry and friction coefficient measurements as a function of entrainment velocity. The authors showed that for blends of high viscosity esters in low viscosity hydrocarbons, ester accumulation and consequent viscosity increase at the near surface increased EHD film thickness so that the transition between EHD and boundary lubrication occurred at lower entrainment velocities. For low viscosity esters in higher viscosity hydrocarbons the opposite was observed. 
Stribeck curves ((20)) are used to identify lubrication mechanisms as a function of load, velocity, viscosity and surface roughness. They present friction coefficient as a function of the non-dimensional parameter $\eta V / F_{N}$, where $\eta$ is the lubricant viscosity, $V$ is the entrainment velocity and $F_{N}$ is the normal load. This parameter dictates hydrodynamic film thickness, which, when compared with the surface roughness of the two surfaces defines the lubrication regime, varying from full-film hydrodynamic regime to mixed and then to boundary lubrication as the value of the parameter is reduced. If ethanol fractionation occurs, this may shift the transition between mixed lubrication and boundary lubrication to conditions where mixed lubrication is normally expected to occur, since ethanol has a viscosity much lower than the lubricant.

As well as their possible impact on hydrodynamic film thickness, it is also quite likely that ethanol or its water component will influence the formation of boundary lubricating films. Friction modifier and antiwear additives are used in engine oils to reduce boundary friction and wear respectively. Both function by forming adsorbed or reacted protective films that serve to prevent direct contact between opposing, rubbing ferrous surfaces when the latter are not separated by a hydrodynamic oil film. In order to adsorb on metal surfaces these additives are more polar than the base oil and it is possible that ethanol and water, which are both very polar, may competitively adsorb on surfaces, or even solubilise additive boundary films that form on these surfaces. 


\section{MATERIALS AND METHODS}

\section{Materials}

Both engine oil and its corresponding base oils were studied in order to separate the effects of ethanol on the base oil from its interactions with additives present in fully formulated oil. A Group I base oil was selected, since this is the main base oil currently used in Brazil for the production of lubricants. For comparison, film thickness measurements were also carried out using a Group II base oil.

The formulated oil was SL classification without friction modifiers and is denoted SLB in this paper. The main metallic components in this oil are listed in Table I. They suggest the presence of a zinc dithiophosphate-based anti-wear additive and a calcium sulphonatebased detergent.

Small amounts of ethanol were added to the lubricants to investigate the effects of ethanol contamination. For tests with the base oils, the amount was $2 \%$ wt., but the measurement of the amount of ethanol at the end of the tests (see section 2.4) showed a considerable reduction of the amount of ethanol during high temperature tests and therefore this amount was increased to 5\% wt. for the formulated oil.

In Brazil, hydrated ethanol produced via sugar cane sugar fermentation is used in flex-fuel engines. However, when added to gasoline, such as in E85, anhydrous ethanol is employed, since water is not soluble in gasoline. The effect of the water present in hydrated ethanol was evaluated by carrying out tests with both hydrated (HE) and anhydrous ethanol (AE). 
All the fluid samples investigated in this work, their abbreviations used throughout the paper and the symbols used to represent them in the graphs shown in the Results sections are presented in Table II. This table also shows the addition of ethanal (ETA) and acetic acid (AA) to Group I base oils, and refers to a few additional tests carried out to help interpret the main results. Heating of capped vials containing samples of the blends on a hot plate at different temperatures showed that $5 \%$ wt. of AE was soluble in base oil at both $40^{\circ} \mathrm{C}$ and $100^{\circ} \mathrm{C}$, but that $\mathrm{HE}$ was insoluble at both temperatures. In the case of formulated oil, $5 \%$ of $\mathrm{AE}$ was soluble at both $40^{\circ} \mathrm{C}$ and $100^{\circ} \mathrm{C}$, but $\mathrm{HE}$ remained insoluble over the whole temperature range.

Viscosities and densities were measured for the oils and their blends with ethanol using a SVM3000 Stabinger viscometer at the three test temperatures of $40^{\circ} \mathrm{C}, 70^{\circ} \mathrm{C}$ and $100^{\circ} \mathrm{C}$. Table III shows that the addition of HE reduced viscosity for the Group I and II base oils and for the formulated oil at $40^{\circ} \mathrm{C}$ and $70^{\circ} \mathrm{C}$. At $100^{\circ} \mathrm{C}$, it was not possible to measure the viscosity of the mixtures containing ethanol due to the formation of a large number of bubbles in the measurement tube, probably resulting from evaporation of ethanol. AE, when added to the oils, reduced viscosity more than HE.

\section{EHL Film Thickness Measurements}

Ultrathin interferometry was used to measure EHL film thickness at different rolling speeds and temperatures for the oils and their blends with ethanol. A contact is formed between the flat surface of a glass disc and a reflective steel ball. The glass disc is sputter-coated with a thin, semi-reflecting layer of chromium, and subsequently with a thin silica spacer layer. Some of the white light shone into the contact is reflected from the chromium layer whilst 
some passes through the spacer layer and any lubricant film present before being reflected from the steel ball. The two beams recombine and optically interfere. The interfered light from a strip across the contact is then passed into a spectrometer where it is dispersed by wavelength and detected by a solid-state, black and white TV camera. A frame grabber is used to capture this image and a microcomputer program determines the wavelength of maximum constructive interference either in the central region of the contact or as a profile across the contact. The lubricant film thickness is then calculated from the difference between the measured film thickness and the thickness of the silica spacer layer at the position of image capture (Johnston, et al. (21)).

Both ball and disc can be independently driven, but in this work the disc was rotated and drove the ball in nominally pure rolling. AISI 52100 steel balls of diameter $19 \mathrm{~mm}$ and nominal root mean square surface roughness $\mathrm{R}_{\mathrm{q}}$ between 10 to13 $\mathrm{nm}$ were used. The applied load was $20 \mathrm{~N}$, which produces a maximum contact pressure of $0.52 \mathrm{GPa}$. A new steel ball was used for each test. Disc, ball and test chamber were thoroughly rinsed using Analar toluene followed by Analar isopropanol prior to each test.

The test sequence was as follows: first, a test was carried out at $40^{\circ} \mathrm{C}$, followed by a test at $100^{\circ} \mathrm{C}$ within the same test sequence, i.e., the balls and disk were not cleaned between the tests at $40^{\circ} \mathrm{C}$ and $100^{\circ} \mathrm{C}$, nor was the lubricant sample changed. In the tests, mean rolling speed was increased from $1 \mathrm{~mm} / \mathrm{s}$ to $1000 \mathrm{~mm} / \mathrm{s}$ in 31 stages. At each speed stage, at least three film thickness values were measured successively and averaged. For all of the samples tested in this work, at least three repeat tests were carried out. 


\section{Friction Measurements}

Friction tests were carried out using a Mini Traction Machine (MTM) ball on disk test. Ball and disc are driven by two independent DC motors so that any combination of rolling and sliding can be obtained. In this study, friction was measured over a range of entrainment speeds (mean rolling speed) at a fixed slide roll ratio $(S R R)$ to obtain Stribeck curves. SRR, which was held constant at a value of $50 \%$, is defined as $\left(U_{\text {ball }}-U_{\text {disk }}\right) / U$, where $\left|U_{\text {ball }}-U_{\text {disk }}\right|$ is the sliding speed and $U$ is the entrainment or mean rolling speed, given by $U=\left(U_{\text {ball }}+\right.$ $\left.U_{\text {disk }}\right) / 2$. When SRR $=0 \%$ (i.e. $U_{\text {ball }}=U_{\text {disk }}$ ), pure rolling contact occurs and when SRR $=$ 200\% (i.e. either $U_{\text {ball }}$ or $U_{\text {disk }}=0$ ), pure sliding contact occurs, while values between 0 and 200\% represent mixed sliding/rolling contact (Lee, et al. (22)). The tests started at a mean rolling speed of $1000 \mathrm{~mm} / \mathrm{s}$, which was continuously reduced (in 31 logarithmically-spaced stages) down to $1 \mathrm{~mm} / \mathrm{s}$. The disc was fully-immersed in lubricant and the temperature of the lubricant and contact was controlled to a set value within $\pm 0.5^{\circ} \mathrm{C}$. Set temperatures of $40^{\circ} \mathrm{C}, 70^{\circ} \mathrm{C}$ and $100^{\circ} \mathrm{C}$ were studied. The balls were AISI 52100 bearing steel with diameter 19 mm, Young's modulus $210 \mathrm{GPa}$ and nominal $\mathrm{R}_{\mathrm{q}}$ between 10 and13 nm while the discs were AISI 52100 steel with nominal $\mathrm{R}_{\mathrm{q}}$ between 25 and30 nm. The load applied was $20 \mathrm{~N}$, corresponding to a maximum Hertz pressure of $0.82 \mathrm{GPa}$. Fresh balls and disks were used in each test, which were ultrasonically cleaned in Analar toluene followed by Analar acetone prior to a test. The rig was cleaned using toluene followed by Analar isopropanol before each test. The choice of temperatures for the tests tried to cover a range that was relevant during the use of car engines, but that could still allow some ethanol to be retained in the lubricant. 


\section{Measurement of the Amount of Ethanol in the Lubricant}

Since the evaporation point of ethanol is relatively low $\left(69^{\circ} \mathrm{C}\right)$, it was necessary to evaluate if some ethanol remained in the lubricant at the end of the tests when they were carried out at higher temperatures.

Due to the low molecular weight and high polarity of ethanol, it can be extracted from the lubricant after the tests by aqueous extraction (Pauls and McCoy (23)). For this, $12 \mathrm{ml}$ of the oil sampled after the tests were accurately weighed into a vial and $2 \mathrm{ml}$ of distilled water were added. The vial was capped and shaken gently to avoid emulsification. After the phases separated, the bottom aqueous layer was sampled using a clean syringe. After sampling of the water layer, refractive index measurements were used to assess the amount of ethanol in the water. Refractive index measurements are very simple, fast and precise and small amounts of ethanol can produce measurable variations in the refractive index of distilled water (Nowakowska (24)). Calibration of the procedure was carried out by measuring refractive index of the bottom aqueous layer of mixtures of $12 \mathrm{ml}$ of lubricant containing $0 \%, 0.5 \%, 1 \%, 2 \%, 3 \%$ and $5 \%$ wt. of ethanol (AE and $\mathrm{HE}$ ) with $2 \mathrm{ml}$ of distilled water, using the above procedure. All refractive index measurements were performed at $30^{\circ} \mathrm{C}$. An example of a calibration curve is shown in Figure 1 for different additions of hydrated ethanol to the Group I base oil. 


\section{RESULTS}

\section{Influence of Ethanol on EHL Film Thickness Behaviour of Base and Formulated Oils}

Figure 2 plots log (film thickness) vs. log (entrainment speed) to analyse the effect of adding $2 \%$ of hydrated ethanol (HE) to a group I base oil at $40^{\circ} \mathrm{C}$. The base oil shows an approximately linear relationship between log (film thickness) and log (entrainment speed) for the whole range of speeds tested, in accord with EHD theory. When HE ethanol is added, a slightly thicker film is observed at low speeds (less than around $10 \mathrm{~mm} / \mathrm{s}$ ), where mixed and boundary lubrication prevails.

In Figure 3, the effect of the addition of both HE and anhydrous ethanol (AE) on film thickness is shown for tests at $100^{\circ} \mathrm{C}$. Both $\mathrm{AE}$ and $\mathrm{HE}$ generate a thin boundary film, between 2 and $5 \mathrm{~nm}$ thick, which is not present with the ethanol-free base oil. Also, results of film thickness when ethanol was added were more scattered than for the ethanol-free base oil.

For comparison, AE and HE were also added to a group II base oil and the results for tests at $100^{\circ} \mathrm{C}$ are shown in Figure 4. This figure again shows that both $\mathrm{AE}$ and HE produce thicker films in the low speed region than the base oil and more scattered results when ethanol was present in the lubricant. However, the effects of HE and AE are retained up to a higher rolling speed.

For the formulated oil, film thickness measurements at temperatures of $40^{\circ} \mathrm{C}, 70^{\circ} \mathrm{C}$ and $100^{\circ} \mathrm{C}$ are shown initially, in order to understand the behaviour of the formulated oil without ethanol contamination (Figure 5). This figure also shows plots of the predicted film 
thickness for each temperature based on the Hamrock and Dowson equation for an EHL elliptical contact (Hamrock and Dowson (25)). The values for the pressure-viscosity coefficients were estimated from (Linde (8)), while $E_{\text {steel }}=203 \mathrm{GPa}, E_{\text {silica }}=72 \mathrm{GPa}, \nu_{\text {steel }}=$ $0.3, v_{\text {silica }}=0.2$ (Lee, et al. (22)). The experimental results suggest the formation of a boundary film of thickness ca 8-9 $\mathrm{nm}$ at all temperatures tested. Comparison with the theoretical curves show that at $40^{\circ} \mathrm{C}$ the measured values agree well with the predictions at the higher speeds. When the temperature increases and therefore film thickness decreases, the measured values are higher than the predicted, but the difference reduces as the speed increases and remains approximately $10 \mathrm{~nm}$. This suggests that the boundary film remains on the sliding surfaces at relatively high speeds.

Figure 6 shows that the addition of ethanol reduces film thickness of the formulated oil for the whole range of speeds investigated. The reduction in film thickness in the mixed and full film lubrication regimes is slightly larger for AE than for HE, which agrees with the viscosity measurements of the mixtures. In the boundary regime, a thinner boundary layer is present than seen with the formulated oil for both $\mathrm{AE}$ and HE. Comparison of the measured values with predicted EHD film thicknesses using the measured viscosities suggests that when ethanol is added the measured and predicted values are close, although the measured values are slightly lower. It is probable that the slight differences must be due to the impact of dissolved ethanol on viscosity-pressure coefficient. The measured values only deviate from a straight line at very low speeds, below $3 \mathrm{~mm} / \mathrm{s}$, where a thin boundary film of around 3 to $5 \mathrm{~nm}$ is seen, similar to the behaviour found for the base oil. These 
results suggest that the presence of ethanol inhibits the formation of the thick boundary film otherwise formed for the formulated oil, but still allows a thin boundary layer.

A similar influence of the addition of $\mathrm{AE}$ and $\mathrm{HE}$ was found at $70^{\circ} \mathrm{C}$, as shown in Figure 7. At this temperature, no difference between AE and HE could be detected for the highest speeds.

At $100^{\circ} \mathrm{C}$, again both $\mathrm{AE}$ and $\mathrm{HE}$ reduce film thickness for the whole range of speeds investigated, but no difference was detected between HE and AE, as shown in Figure 8. Also, film thickness values for the lubricant containing ethanol were fairly more scattered, as observed for the base oils.

\section{Influence of Ethanol on Stribeck Friction Curves for Base and Formulated Oils}

Figure 9 shows a plot of friction coefficient vs. $\log$ (entrainment speed) at $40^{\circ} \mathrm{C}$ (Stribeck curve) comparing a Group I base oil and a mixture containing 2\% HE. At high speeds, an approximately constant plateau is reached, where friction is independent of the entrainment speed. In this region, a slight reduction is observed in the friction coefficient when ethanol is added. Film thickness measurements at $40^{\circ} \mathrm{C}$ under pure rolling showed a slightly thinner film in the high speed region for the mixture with ethanol, which probably justifies the friction reduction. In the region of intermediate speeds (mixed lubrication), the mixture with HE presents slightly higher friction, but the difference is very small. The boundary lubrication regime does not seem to have been fully achieved at this temperature at the lowest speeds attained, so no significant effect of the addition of hydrated ethanol was observed at the lowest speeds. 
At $70^{\circ} \mathrm{C}$ (Figure 10), the addition of HE caused a slight increase in friction in the mixed lubrication regime. The thinner film due to the decrease in viscosity may cause more contact between the asperities of the surfaces, which could explain the slight increase in friction coefficient. At the lowest speeds, the presence of HE decreased friction coefficients slightly, suggesting the formation of a boundary film.

Stribeck curves obtained at $100^{\circ} \mathrm{C}$ are shown in Figure 11. The base oil approaches a plateau, corresponding to full film EHD lubrication, at the highest speeds, but friction coefficient increases as the speed reduced indicating mixed lubrication. The addition of HE has no effect on friction coefficient at high speeds, but for AE a plateau was no longer detected for the highest speeds. It appears that the transition from full film EHD lubrication to mixed lubrication occurs at a higher speed for the blend with AE than for the base oil or the HE blend. This probably originates from the lower viscosity of the AE blend, which leads to thinner films and therefore more asperity contact. At low speeds, the formation of a boundary film that stabilizes friction coefficient at around 0.15 is very clear for both HE and AE, and is not present for the base oil.

The effects of ethanol contamination on friction for the formulated oils were similar to those observed for the base oils under conditions where full film or mixed lubrication prevailed, but different in the boundary lubrication regime. As examples, the effects of ethanol contamination on Stribeck curves for the formulated oil SLB at $70^{\circ} \mathrm{C}$ (Figure 12) and $100^{\circ} \mathrm{C}$ (Figure 13) are presented.

At $70^{\circ} \mathrm{C}$ (Figure 12), the addition of ethanol reduced friction coefficients in the high speed region, where a plateau is reached. The reduction in friction coefficient follows the 
reduction in viscosity, which was greater for AE blend than for HE blend, as observed for the base oils. However, in the low speed range, where boundary lubrication occurs, HE increased friction. The EHD tests under pure rolling showed a thinner boundary film in the presence of ethanol. Therefore, ethanol seems to interfere with the formation of the boundary layer, leading to a thinner boundary film and also to higher friction.

At $100^{\circ} \mathrm{C}$ (Figure 13), in the region of mixed lubrication, the addition of ethanol increases friction and the increase is slightly higher for AE than for HE. This can be attributed to the reduction in viscosity caused by the presence of $\mathrm{AE}$ and $\mathrm{HE}$, because thinner films enable more metal contact. AE and HE appear to suppress some boundary film formation, slightly increasing friction coefficient at low speeds, as seen for tests both at $70^{\circ} \mathrm{C}$ (Figure 12) and $100^{\circ} \mathrm{C}$ (Figure 13).

\section{Amount of Ethanol after the Tests}

At the end of each test the amount of ethanol present in the lubricant was determined using refractive index measurements of the ethanol extracted with water, as described in Section

\subsection{The results are shown in Table IV.}

Measurements were also carried out on the ethanol-free oils after testing. All of the latter gave the same value of 1.3330 , which is the value of the refractive index of distilled water found in the literature (Nowakowska (24)).

For the EHD tests there was some loss of ethanol at $100^{\circ} \mathrm{C}$ but more than half of the ethanol content remained to the end of the tests. This is because the EHD test apparatus had a good seal and the volume of oil used during the tests was relatively large (around $150 \mathrm{ml}$ ). The 
reduction in the amount of ethanol due to evaporation during the MTM tests at $100^{\circ} \mathrm{C}$ was much higher than for the EHD tests. This emphasizes the importance of running tests at intermediate temperatures, such as $70^{\circ} \mathrm{C}$, which is just above the evaporation point of ethanol, and yet high enough for some of the antiwear additive present in the formulated oil to be effective.

\section{DISCUSSION}

The results show that the effect of contamination with ethanol on friction and film thickness is similar for the base oil and for the formulated oil when the contact operates in mixed and/or full film lubrication. On the other hand, in the boundary lubrication regime, the effect of the presence of ethanol in the base oil is very different from that in the formulated oil. The two different situations are discussed in this section.

When ethanol is added to the base oil and to the formulated oil, it reduces friction at high speeds in the full film EHD lubrication regime characterised by the friction levelling out at a relatively low value $\left(\mu_{L}\right)$ (Evans and Johnson (26, Evans and Johnson (27)). Under these conditions, friction depends only on the molecular structure of the lubricant and its free volume. In general, the reduction in $\mu_{L}$ was found to be higher for AE than for HE, while measurements also showed lower viscosities for blends with AE than with HE. This suggests that the addition of ethanol confers a greater free volume, enabling lubricant molecules slide more easily in relation to each other, reducing both viscosity and $\mu_{L}$ and that this effect is more significant for AE than for HE. Although the viscosity of pure ethanol is higher than that of water, we hypothesize that when both water and ethanol are 
present the true solubility of the ethanol in hydrocarbon is reduced, resulting in some of the ethanol being present as a microemulsion, thereby having little influence on viscosity. However, this effect needs to be further investigated and explained.

(De Silva, et al. (15)) also detected a small reduction of mean friction coefficient measured in lubricated reciprocating tests due to the presence of ethanol and water in a fully formulated oil. However, since the authors measured mean friction coefficient, it was not possible to identify if this reduction occurred in the middle of the stroke, where a full film may be present, or in reversal regions where mixed and/or boundary lubrication prevails. Also, since only formulated oil was studied it was not possible to identify the extent to which the interaction of ethanol occurred with the base oil or with additives present in a fully formulated oil, such as detergents, anti-wear additives and friction modifiers.

In the MTM tests, as speed and thus EHD film thickness is reduced, friction increased for all the fluids tested, as the contact enters the mixed lubrication regime. In this region, the addition of ethanol increases friction coefficient compared to the ethanol-free fluids, both for the base oil and for the formulated oil. Also, a slight reduction in film thickness in pure rolling was detected due to the addition of ethanol to the base oils and to the formulated oil for tests conducted at lower temperature and higher rolling speeds. This film thickness reduction seems then to be related to the reduction in the viscosity of the lubricant due to the presence of ethanol, which was more significant for AE than for HE. Thinner films may cause more contact between the asperities of the surfaces, which may explain the increase in friction coefficient observed, in particular, with AE. 
At very low speeds, especially when combined with higher temperatures, and therefore very thin EHL films, the presence of ethanol seems to promote the formation of a boundary layer that is not present for the ethanol-free base oils under pure rolling. Also, Stribeck curves showed a small reduction of friction in the regions of very thin EHL film thickness when ethanol is present in the base oil, also suggesting the formation of a boundary film.

One possible explanation of the formation of a boundary layer due to the addition of ethanol could be the fractionation of ethanol to the metallic surfaces, due to its higher polarity when compared with the base oil lubricant. However, since ethanol is less viscous than the oil, the boundary layer should be thinner. Therefore, the hypothesis of fractionation of ethanol molecules to the metal surface due to their higher polarity must be discarded. Another possibility could be reaction or deposition of oxidation products on the hot metal surface. In order to investigate this, some film thickness measurements were carried out in which small amounts (2\%wt.) of ethanal (ETA), which is the first, and acetic acid (AA), which is the second oxidation product of ethanol, were added to the Group I base oil. Both ethanal and acetic acid were soluble in this base oil at room temperature. The results are shown in Figures 14 and 15 for tests at $40^{\circ} \mathrm{C}$ and $100^{\circ} \mathrm{C}$, respectively.

At $40^{\circ} \mathrm{C}$, the reduction in film thickness due to the addition of ethanal in the full film region was slightly larger than that due to the addition of ethanol, as shown in Figure 14. However, in the boundary region, boundary films of similar thicknesses seem to form with both hydrated ethanol and ethanal.

Figure 15 shows results at $100^{\circ} \mathrm{C}$, for ethanal, acetic acid and anhydrous ethanol. The effects of AE and ethanal were very similar. However, the addition of acetic acid produced 
thicker films for the whole range of speeds tested. Also, apparent oxidation could be observed on the balls after the tests.

Another interesting feature with the addition of acetic acid is that when consecutive tests were carried out using the same ball, disk and lubricant, film thickness increased continuously from test to test for all speeds tested, as shown in Figure 16, where T1 to T5 are five consecutive tests on the same wear track. Also, the ball seemed severely oxidized after the tests, suggesting the formation of an oxide film on the ball. In future work, surface analysis would help determine the nature of the boundary film formed under these conditions.

For the formulated oil, in the absence of ethanol, film thickness measurements show the clear formation of a boundary film of thickness ca $9 \mathrm{~nm}$. This forms at all temperatures and is solid-like in the sense that it appears to continue to augment the film even at high speeds when the overall film thickness is much greater than $9 \mathrm{~nm}$. This film is almost certainly produced mechanically by the adhesion and accumulation of overbased detergent particles present in the oil, as described by (Topolovec-Miklozic, et al. (28)). Since calcium was present in the oil as indicated in Table 1, it probably consists primarily of calcium carbonate. Thick boundary films are also formed by the antiwear additive ZDDP, which was also present in the formulated lubricant, but the formation of these generally requires considerable sliding to take place (Fujita and Spikes (29)). Thick film formation by ZDDP in nominally pure rolling conditions only occurs at temperatures well above $100^{\circ} \mathrm{C}$ (Gunsel, et al. (30)). 
The addition of both hydrated and anhydrous ethanol suppressed this thick boundary film formation, suggesting that ethanol either solubilises the film or prevents the detergent nanoparticless from adhering to the surfaces. To explore this further, two series of MTM friction experiments were carried out at $100^{\circ} \mathrm{C}$, where consecutive Stribeck curves were obtained on the same wear track. Between each Stribeck curve, ball and disk were not removed, but the lubricant was drained and fresh lubricant was added to the test chamber. The results are shown in Figure 17.

For the ethanol-free formulated oil, a friction coefficient of around 0.09 is obtained in the boundary regime, that does not vary during successive Stribeck curve measurements. However, as consecutive curves are obtained, the Stribeck curves shift to the right, i.e., the transition between boundary and full film lubrication occurs at progressively higher speeds. This behaviour suggests the progressive growth of a rough boundary film and has been reported to occur for both overbased detergents (Topolovec-Miklozic, et al. (28)) and ZDDPs (Taylor and Spikes (31, Smeeth, et al. (32)). The growth of an uneven surface film increases the effective roughness of the surfaces, requiring a higher mean rolling speed to generate an inlet pressure and thus a fluid film.

On the other hand, when either AE or HE is added to the oil, this behaviour does not occur. All tests with added ethanol show slightly larger friction in the boundary region, but in particular they do not show the progressive shift in the Stribeck curves. This clearly suggests that the addition of ethanol prevents the formation of thick, rough surface films.

Further investigation is necessary to clarify the exact mechanism by which ethanol hinders the formation of this boundary film, but this work clearly shows that the presence of 
ethanol in formulated oils can be detrimental in the boundary lubrication regime when this oil contains ZDDP and/or Ca-based detergent additives.

A final remark is that film thickness measurements for tests with ethanol were more scattered than for neat lubricants, and scatter was more significant at $100^{\circ} \mathrm{C}$ than at lower temperatures. Due to the low evaporation point of ethanol, it is possible that bubbles may form within the lubricant, as observed during the viscosity measurements at $100^{\circ} \mathrm{C}$ for the blends containing ethanol, which might contribute to such scattering. Also, while in contact with the top glass disk, ethanol may condensate back into the contact. From the experimental point of view, the volume of lubricants used within the test chamber was larger than usual, which reduced the gap between the level of lubricant and the glass disk, in order to reduce ethanol condensation on the disk. However, despite these problems, the tests at $100^{\circ} \mathrm{C}$ were considered appropriate, since it is important to understand the effects of ethanol at higher engine temperatures.

\section{CONCLUSIONS}

The addition of quite small proportions of ethanol decreases the viscosity of both the base and formulated oils, more significantly for AE than for HE. This has the effect of slightly reducing EHD film thickness and friction and causing the shift from full film to mixed

lubrication to occur at a lower entrainment speed, as evidenced by friction measurements.

The effects of ethanol contamination on film thickness and friction were broadly similar for the base and formulated oils for the test conditions in the full film and mixed lubrication 
regimes. However in slow speed, boundary lubrication conditions, the effect of ethanol in the base oil was very different from that of ethanol in the formulated oil.

In base oil the presence of ethanol promoted the formation of a boundary layer that was not present with the ethanol-free base oils. It is suggested that this boundary layer may be due to oxidation of ethanol when in contact with a hot, rubbing metal surface.

In a formulated engine oil, the presence of ethanol interferes with the formation of a thick boundary film, reducing its thickness for ca $9 \mathrm{~nm}$ to $c a 2-3 \mathrm{~nm}$. With ethanol-free base oil, consecutive Stribeck friction curves of the formulated oil showed a progressive shift to the right, indicative of the growth of a thick, rough boundary film, but this was supressed by the addition of both AE and HE.

A new technique using extraction with water and refractive index measurements has been developed to evaluate the amount of ethanol present in a lubricant. The results using this show that the ethanol content during a test is greatly reduced, especially in tests using the MTM rig at high temperatures, probably due to evaporation.

\section{ACKNOWLEDGEMENTS}

The authors are grateful to Petrobras, in particular to Dr. Luis Fernando Lastres, for providing lubricant and hydrated ethanol fuel samples and to CNPq (Brazil) for financial support to H.L.Costa. 


\section{REFERENCES}

(1) Wu, X. S., Daniel, R., Tian, G. H., Xu, H. M., Huang, Z. H. and Richardson, D. (2011), "Dual-injection: The flexible, bi-fuel concept for spark-ignition engines fuelled with various gasoline and biofuel blends,” Appl. Energy 88, 7, pp. 2305-2314.

(2) Bastian-Pinto, C., Brandao, L. and Alves, M. D. (2010), "Valuing the switching flexibility of the ethanol-gas flex fuel car,” Ann. Oper. Res. 176, 1, pp. 333-348.

(3) Cavalcanti, M., Szklo, A. and Machado, G. (2012), "Do ethanol prices in Brazil follow Brent price and international gasoline price parity?,” Renew. Energy 43, pp. 423433.

(4) Ahn, K. H., Stefanopoulou, A. G. and Jankovic, M. (2010), "Puddle Dynamics and Air-to-Fuel Ratio Compensation for Gasoline-Ethanol Blends in Flex-Fuel Engines,” IEEE Trans. Control Syst. Technol. 18, 6, pp. 1241-1253.

(5) Dutcher, D. D., Stolzenburg, M. R., Thompson, S. L., Medrano, J. M., Gross, D. S., Kittelson, D. B. and McMurry, P. H. (2011), "Emissions from Ethanol-Gasoline Blends: A Single Particle Perspective,” Atmosphere 2, 2, pp. 182-200.

(6) 2003/30/EC, D. (2003), "Directive 2003/30/EC of the European Parliament and of the Council of 8 May 2003 on the promotion of the use of biofuels or other renewable fuels for transport ” Editon Edition, European Commission Brussels, ISBN ISBN.

(7) 2009/28/EC, D. (2009), “Directive 2009/28/EC of 23 April 2009 on the promotion of the use of energy from renewable sources and amending and subsequently repealing Directives 2001/77/EC and 2003/30/EC,” Editon Edition, European Commission, Brussels, ISBN ISBN.

(8) Linde, R. a. F., J. (2010), "Emissions and experiences with E85 converted cars in the BEST project,” Editon Edition, Vaxjo, Sweden, ISBN ISBN.

(9) Pelkmans, L., Lenaers, G., Bruyninx, J., Scheepers, K. and De Vlieger, I. (2011), "Impact of biofuel blends on the emissions of modern vehicles," Proc. Inst. Mech. Eng. Part D-J. Automob. Eng. 225, D9, pp. 1204-1220.

(10) Maricq, M. M. (2012), "Soot formation in ethanol/gasoline fuel blend diffusion flames,” Combust. Flame 159, 1, pp. 170-180.

(11) Boons, M., Bulk, R. V. D. and King, T. (2008), “The impact of E85 use on lubricant performance," SAE paper 2008-01-1763.

(12) Chui, G. K., Baker, R. E. and Pinto, F. B. P. (Year), "Lubrication behaviour in ethanol-fueled engines,” Proc. 4th Symposium on Alcohol fuels, Gurujá, Brazil, 1980.

(13) Ferrarese, A., Marques, G., Tomanik, E., Bruno, R. and Vatavuk, J. (2010), "Piston ring tribological challenges on the next generation of flex-fuel engines," SAE Int. J. Engines 3, 2, pp. 85-91.

(14) De Silva, P. R., Priest, M., Lee, P. M., Coy, R. C. and Taylor, R. I. (2011), "Tribometer Investigation of the Frictional Response of Piston Rings when Lubricated with the Separated Phases of Lubricant Contaminated with the Gasoline Engine Biofuel Ethanol and Water,” Tribol. Lett. 43, 2, pp. 107-120.

(15) De Silva, P. R., Priest, M., Lee, P. M., Coy, R. C. and Taylor, R. I. (2011), "Tribometer investigation of the frictional response of piston rings with lubricant 
contaminated with the gasoline engine biofuel ethanol and water,” Proc. Inst. Mech. Eng. Part J.-J. Eng. Tribol. 225, J6, pp. 347-358.

(16) Volcci, G. A. (2007), "Comportamento tribológico do anel de primeiro canalete em motores operando em sistemas flex fuel,” 2007, UFPR, Engenharia Mecânica,

(17) Boons, M., Bulk, R. V. D. and King, T. (2008), “The impact of E85 use on lubricant performance,” SAE paper 2008-01-1763.

(18) Chui, G. K. and Millard, D. H. T. (1981), "Development and testing of crankcase lubricants for alcohol fueled engines,” SAE paper 811203.

(19) Guangteng, G. and Spikes, H. A. (1997), “The control of friction by molecular fractionation of base fluid mixtures at metal surfaces,” Tribol T 40, 3, pp. 461-469.

(20) Stribeck, R. (1902), "Die wesentlichen Eigenschaften der Gleit- und Rollenlager,” Zeitschrift des Vereins Deutscher Ingenieure 36, 46, pp. 1341-1348.

(21) Johnston, G. J., Wayte, R. and Spikes, H. A. (1991), "The Measurement and Study of Very Thin Lubricant Films in Concentrated Contacts,” Tribol T 34, 2, pp. 187-194.

(22) Lee, S., Muller, M., Ratoi-Salagean, M., Voros, J., Pasche, S., De Paul, S. M., Spikes, H. A., Textor, M. and Spencer, N. D. (2003), "Boundary lubrication of oxide surfaces by Poly(L-lysine)-g-poly(ethylene glycol) (PLL-g-PEG) in aqueous media,” Tribol. Lett. 15, 3, pp. 231-239.

(23) Pauls, R. E. and McCoy, R. W. (1981), "Gas and liquid-chromatographic analyses of methanol, ethanol, tert-butanol, and methyl tert-butyl ether in gasoline,” J. Chromatogr. Sci. 19, 11, pp. 558-561.

(24) Nowakowska, J. (1939), “The Refractive Indices of Ethyl Alcohol and Water Mixtures,” Master's Thesis 1939, Loyola University Chicago,

(25) Hamrock, B. T. and Dowson, D. (1981), "Ball bearing lubrication: The elastohydrodynamics of elliptical Contacts,” Editon Edition, Wiley, New York, ISBN.

(26) Evans, C. R. and Johnson, K. L. (1986), "The rheological properties of elastohydrodynamic lubricants," Proceedings of the Institution of Mechanical Engineers

Part C-Journal of Mechanical Engineering Science 200, 5, pp. 303-312.

(27) Evans, C. R. and Johnson, K. L. (1986), "Regimes of traction in elastohydrodynamic lubrication,” Proceedings of the Institution of Mechanical Engineers Part C-Journal of Mechanical Engineering Science 200, 5, pp. 313-324.

(28) Topolovec-Miklozic, K., Forbus, T. R. and Spikes, H. A. (2008), "The film-forming and friction properties of overbased calcium sulphonate detergents,” Trib. Letters 29, pp. 33-44.

(29) Fujita, H. and Spikes, H. A. (2004), “The formation of zinc dithiophosphate antiwear films,” Proc. Inst. Mech. Eng. Part J.-J. Eng. Tribol. 218, J4, pp. 265-277.

(30) Gunsel, S., Spikes, H. A. and Aderin, M. (1993), "In-situ measurement of ZDDP films in concentrated contacts,” Trib. Trans. 36, pp. 276-282.

(31) Taylor, L. J. and Spikes, H. A. (2003), "Friction-enhancing properties of ZDDP antiwear additive: Part I - Friction and morphology of ZDDP reaction films,” Tribol T 46, 3, pp. 303-309.

(32) Smeeth, M., Hamer, C. and Spikes, H. A. (2008), “A study of antiwear additive film build up using the MTM (mini-traction machine)," Editon Edition, ISBN 978-0-7918-48104. 


\section{TABLE CAPTIONS}

Table I. Chemical composition of the formulated oil, in ppm.

Table II. List of fluid samples and abbreviations.

Table III. Viscosity measurements for the oils contaminated with ethanol, where $\rho$ is the density, $\eta$ is the dynamic viscosity, $\mathrm{VI}$ is the viscosity index, HE is hydrated ethanol, $\mathrm{AE}$ is anhydrous ethanol, GI is Group I, GII is Group II, N.M. is not measurable.

Table IV. Amounts of ethanol (wt. \%) after tests; B.O. = base oil; F.O. = formulated oil. 


\section{FIGURE CAPTIONS}

Figure 1. Example of calibration curve between refractive index measurements and amount of HE in Group I base oil.

Figure 2. Effect of addition of hydrated ethanol (HE) on film thickness for Group I base oil at $40^{\circ} \mathrm{C}$.

Figure 3. Effect of addition of hydrated ethanol (HE) and anhydrous ethanol (AE) on film thickness for Group I base oil at $100^{\circ} \mathrm{C}$.

Figure 4. Effect of addition of hydrated ethanol (HE) and anhydrous ethanol (AE) on film thickness for Group II base oil at $100^{\circ} \mathrm{C}$.

Figure 5. Film thickness measurements for the formulated oil SLB at $40^{\circ} \mathrm{C}, 70^{\circ} \mathrm{C}$ and $100^{\circ} \mathrm{C}$.

Figure 6. Effect of addition of ethanol to formulated oil SLB on film thickness at $40^{\circ} \mathrm{C}$.

Figure 7. Effect of addition of ethanol to formulated oil SLB on film thickness at $70^{\circ} \mathrm{C}$.

Figure 8. Effect of addition of ethanol to formulated oil SLB on film thickness at $100^{\circ} \mathrm{C}$.

Figure 9. Effect of hydrated ethanol on Stribeck curves for Group I base oil, $40^{\circ} \mathrm{C}$.

Figure 10. Effect of hydrated ethanol on Stribeck curves for Group I base oil, $70^{\circ} \mathrm{C}$.

Figure 11. Effect of ethanol on Stribeck curves for Group I base oil, $100^{\circ} \mathrm{C}$.

Figure 12. Effect of ethanol on Stribeck curves for the formulated oil SLB, $70^{\circ} \mathrm{C}$.

Figure 13. Effect of ethanol on Stribeck curves for the formulated oil SLB, $100^{\circ} \mathrm{C}$.

Figure 14. Effect of addition of ethanal on film thickness for Group I base oil at $40^{\circ} \mathrm{C}$.

Figure 15. Effect of addition of acetic acid and ethanal on film thickness for Group I base oil at $100^{\circ} \mathrm{C}$.

Figure 16. Five consecutive film thickness measurements for mixture of Group I base oil + acetic acid at $100^{\circ} \mathrm{C}$.

Figure 17. Effect of the addition of ethanol on consecutive Stribeck curves for the formulated oil SLB at $100^{\circ} \mathrm{C}$. 


\begin{tabular}{lllllll}
\hline Element & Ca & Mo & P & S & Pb & Zn \\
& & & & & & \\
\hline Amount (ppm) & 1831 & $<1$ & 786 & 4300 & $<10$ & 954 \\
\hline
\end{tabular}

Table I. Chemical composition of the formulated oil SLB, in ppm. 


\begin{tabular}{|c|c|c|c|c|}
\hline \multicolumn{3}{|c|}{ Description } & Abbreviation & Symbol \\
\hline \multirow{8}{*}{ Base oils } & \multirow{5}{*}{$\begin{array}{l}\text { Group I } \\
\text { base oil }\end{array}$} & Neat & GI & 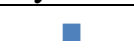 \\
\hline & & 2\% wt. Hydrated Ethanol & GI $2 \% \mathrm{HE}$ & $\boldsymbol{\Delta}$ \\
\hline & & 2\% wt. Anhydrous Ethanol & GI $2 \% \mathrm{AE}$ & $\bullet$ \\
\hline & & $2 \%$ wt. Ethanal & GI 2\% ETA & + \\
\hline & & 2\% wt. Acetic Acid & GI $2 \%$ AA & $\mathrm{x}$ \\
\hline & \multirow{3}{*}{$\begin{array}{l}\text { Group II } \\
\text { base oil }\end{array}$} & Neat & GII & $\square$ \\
\hline & & 2\% wt. Hydrated Ethanol & GII $2 \% \mathrm{HE}$ & $\boldsymbol{\Delta}$ \\
\hline & & 2\% wt. Anhydrous Ethanol & GII $2 \% \mathrm{AE}$ & $\cdot$ \\
\hline \multirow{3}{*}{$\begin{array}{l}\text { Formulated } \\
\text { oil }\end{array}$} & \multirow{3}{*}{$\begin{array}{l}\text { SL class, } \\
\text { no friction } \\
\text { modifiers }\end{array}$} & Neat & SLB & 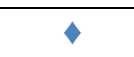 \\
\hline & & 5\% wt. Hydrated Ethanol & SLB 5\%HE & - \\
\hline & & 5\% wt. Anhydrous Ethanol & SLB 5\%AE & $*$ \\
\hline
\end{tabular}

Table II. List of fluid samples, abbreviations and symbols used to represent them in graphs. 


\begin{tabular}{llllll}
\hline Oil & $\begin{array}{l}\rho \text { at } 15^{\circ} \mathrm{C} \\
\left(\mathrm{g} / \mathrm{cm}^{3}\right)\end{array}$ & $\begin{array}{l}\eta \text { at } 40^{\circ} \mathrm{C} \\
\left(\mathrm{mm}^{2} / \mathrm{s}\right)\end{array}$ & $\begin{array}{l}\eta \text { at } 70^{\circ} \mathrm{C} \\
\left(\mathrm{mm}^{2} / \mathrm{s}\right)\end{array}$ & $\begin{array}{l}\eta \text { at } 100^{\circ} \mathrm{C} \\
\left(\mathrm{mm}^{2} / \mathrm{s}\right)\end{array}$ & VI \\
\hline GI & 0.874 & 28.698 & 10.515 & 5.092 & 104.8 \\
GI 2\%AE & 0.871 & 23.773 & 8.707 & N.M. & N.M. \\
GI 2\%HE & 0.873 & 21.218 & 9.679 & N.M. & N.M \\
GII & 0.851 & 20.124 & 7.771 & 4.092 & 102.1 \\
GII 2\%AE & 0.849 & 16.851 & 6.671 & N.M. & N.M. \\
GII 2\%HE & 0.850 & 19.086 & 7.045 & N.M. & N.M. \\
SLB & 0.870 & 97.160 & 30.809 & 13.621 & 141.0 \\
SLB 5\%HE & 0.866 & 89.237 & 24.803 & N.M. & N.M. \\
SLB 5\%AE & 0.865 & 70.259 & 20.732 & N.M. & N.M. \\
\hline
\end{tabular}

Table III. Viscosity measurements for the oils contaminated with ethanol, where $\rho$ is the density, $\eta$ is the kinematic viscosity, VI is the viscosity index, HE is hydrated ethanol, AE is anhydrous ethanol, GI is Group I, GII is Group II, N.M. is not measurable. 


\begin{tabular}{|c|c|c|c|}
\hline \multicolumn{4}{|c|}{ MTM tests } \\
\hline B.O. & $40^{\circ} \mathrm{C}$ & & $100^{\circ} \mathrm{C}$ \\
\hline GI & 0 & & 0 \\
\hline GI $2 \% \mathrm{HE}$ & 1.7 & & 0.15 \\
\hline GI 2\%AE & 2 & & 0.24 \\
\hline F.O. & $40^{\circ} \mathrm{C}$ & $70^{\circ} \mathrm{C}$ & $100^{\circ} \mathrm{C}$ \\
\hline SLB & 0 & 0 & 0 \\
\hline SLB 5\%AE & 4.00 & 2.50 & 0.50 \\
\hline SLB 5\%HE & 3.50 & 2.25 & 0.25 \\
\hline \multicolumn{4}{|c|}{ EHD tests } \\
\hline \multicolumn{4}{|l|}{ B.O. } \\
\hline GI & & 0 & \\
\hline GI 2\%HE & & 1.38 & \\
\hline GI 2\%AE & & 1.27 & \\
\hline \multicolumn{4}{|l|}{ F.O. } \\
\hline SLB & & 0 & \\
\hline SLB 5\%AE & & 2.25 & \\
\hline SLB 5\%HE & & 2.00 & \\
\hline
\end{tabular}

Table IV. Amounts of ethanol (wt. \%) after tests; B.O. = base oil; F.O. = formulated oil. 


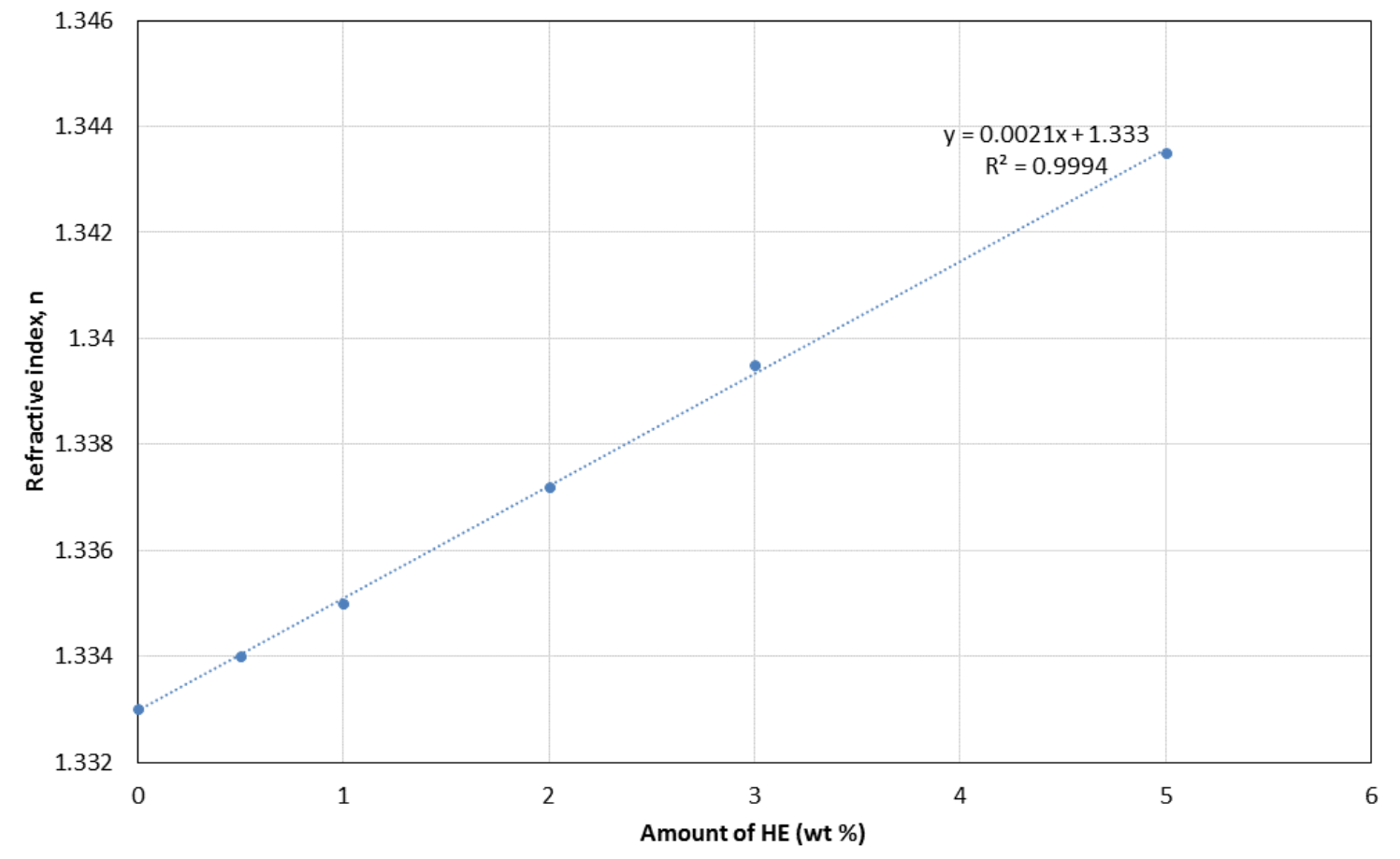

Figure 1. Example of calibration curve between refractive index measurements and amount of HE in Group I base oil. 


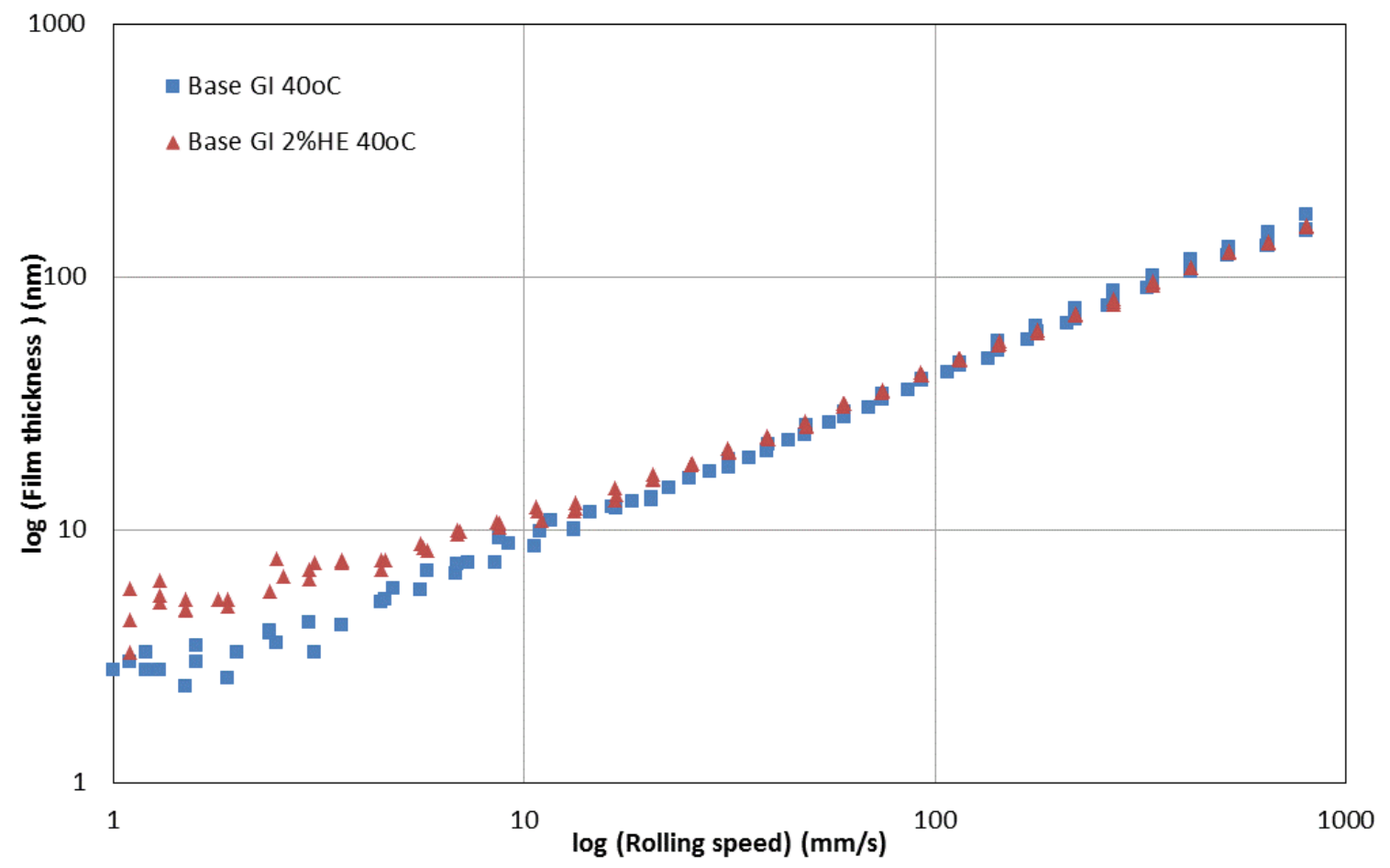

Figure 2. Effect of addition of hydrated ethanol (HE) on film thickness for Group I base oil at $40^{\circ} \mathrm{C}$. 


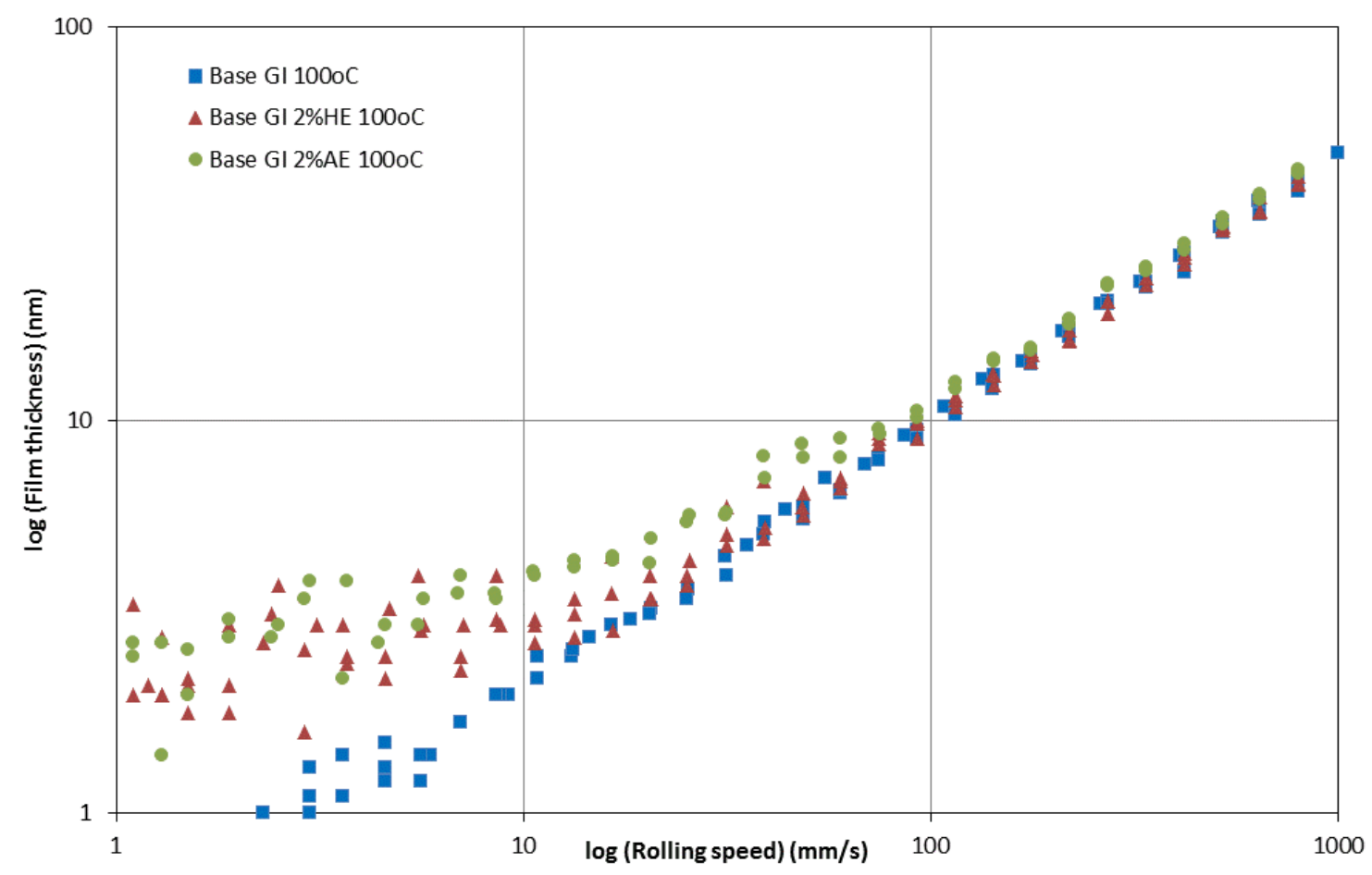

Figure 3. Effect of addition of hydrated ethanol (HE) and anhydrous ethanol (AE) on film thickness for Group I base oil at $100^{\circ} \mathrm{C}$. 


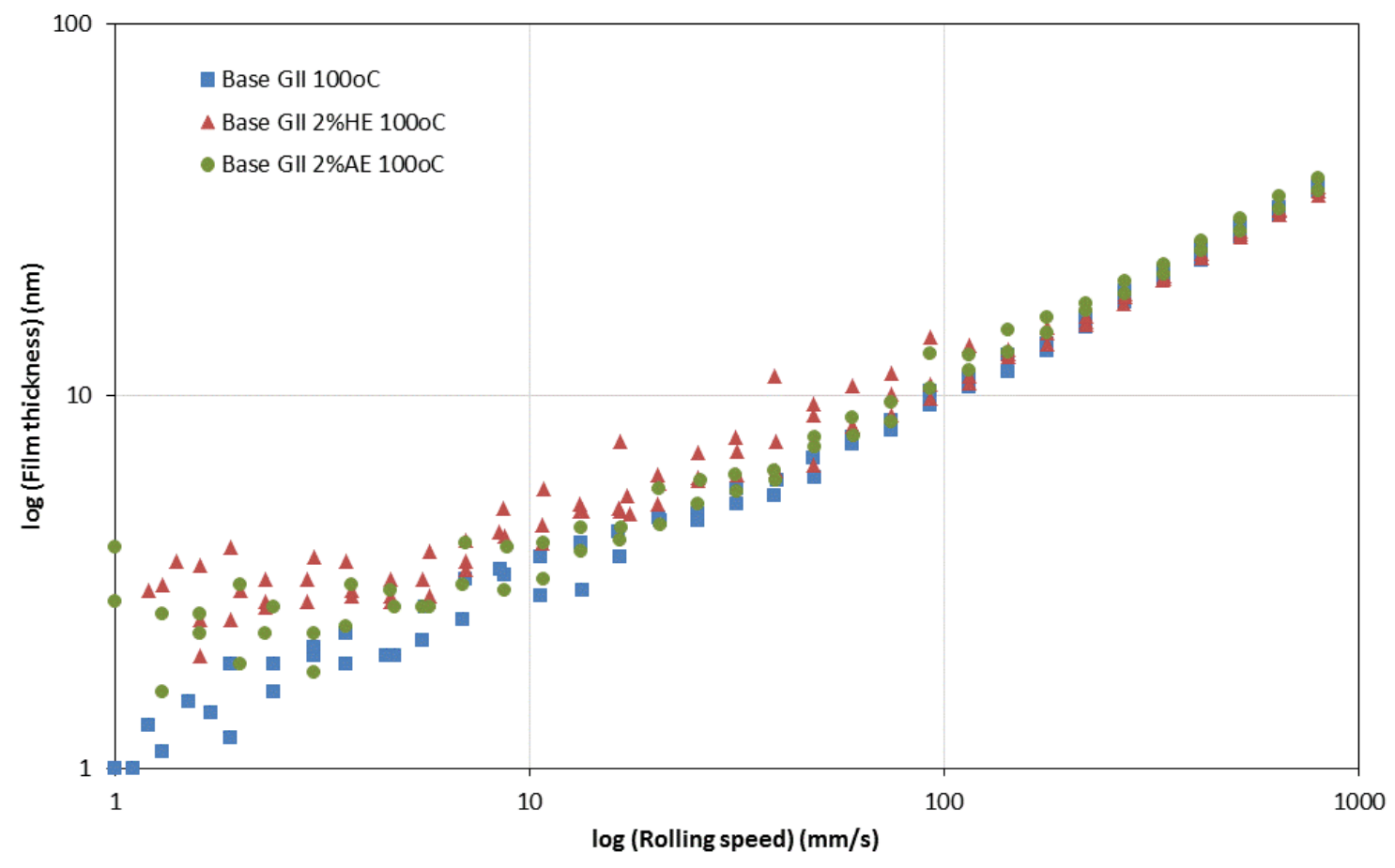

Figure 4. Effect of addition of hydrated ethanol (HE) and anhydrous ethanol (AE) on film thickness for Group II base oil at $100^{\circ} \mathrm{C}$. 


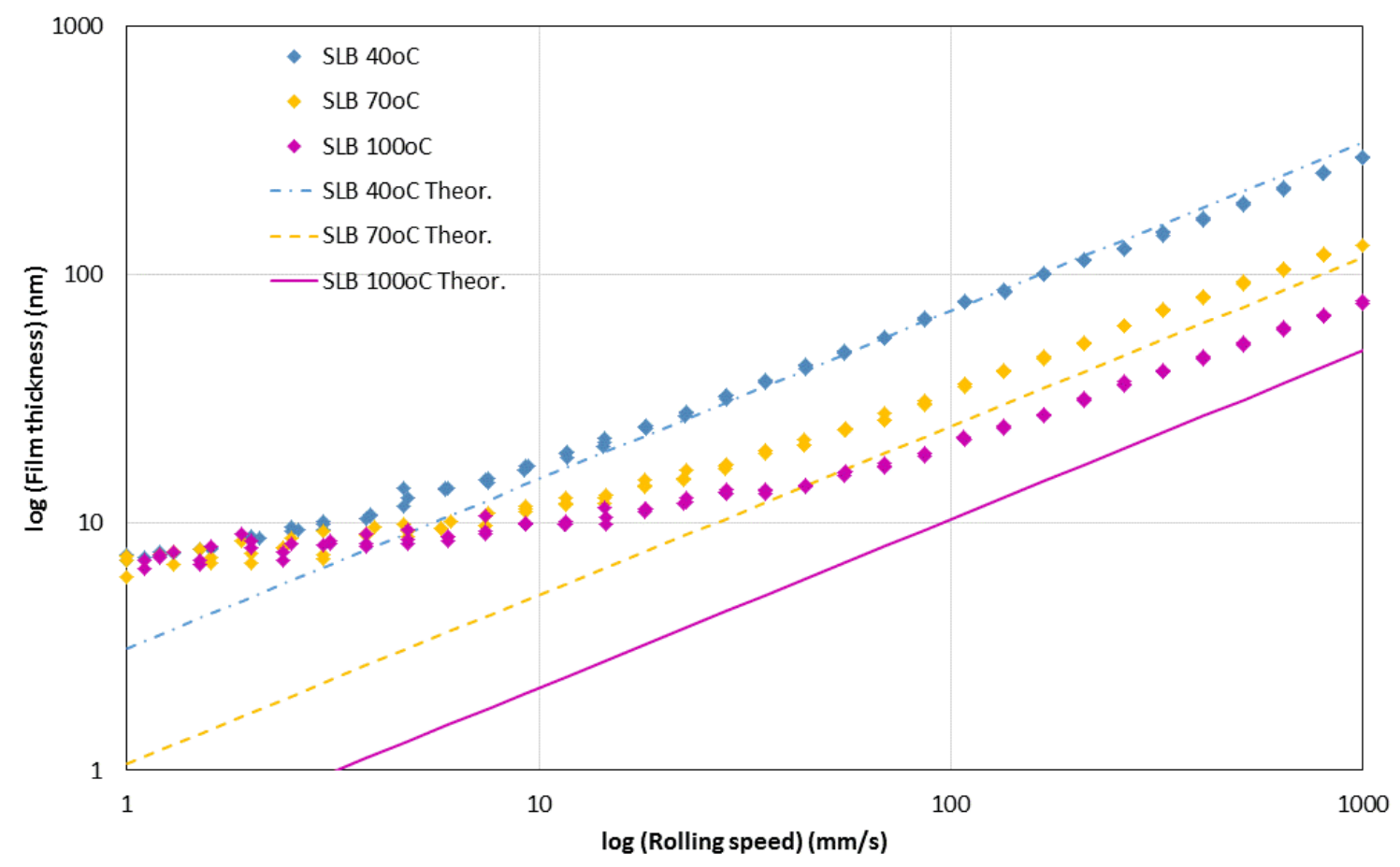

Figure 5. Film thickness measurements for the formulated oil SLB at $40^{\circ} \mathrm{C}, 70^{\circ} \mathrm{C}$ and $100^{\circ} \mathrm{C}$. 


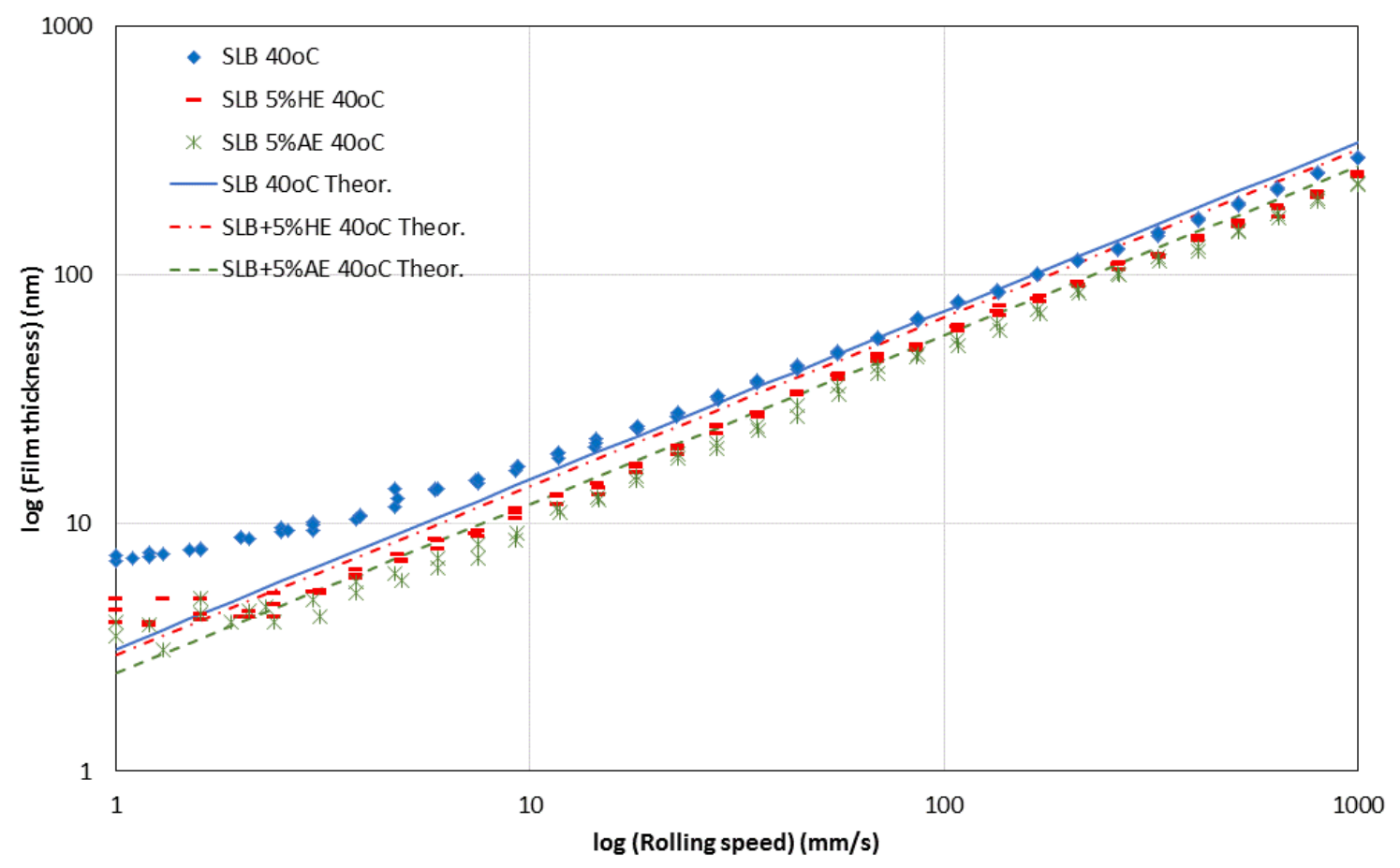

Figure 6. Effect of addition of ethanol to formulated oil SLB on film thickness at $40^{\circ} \mathrm{C}$. 


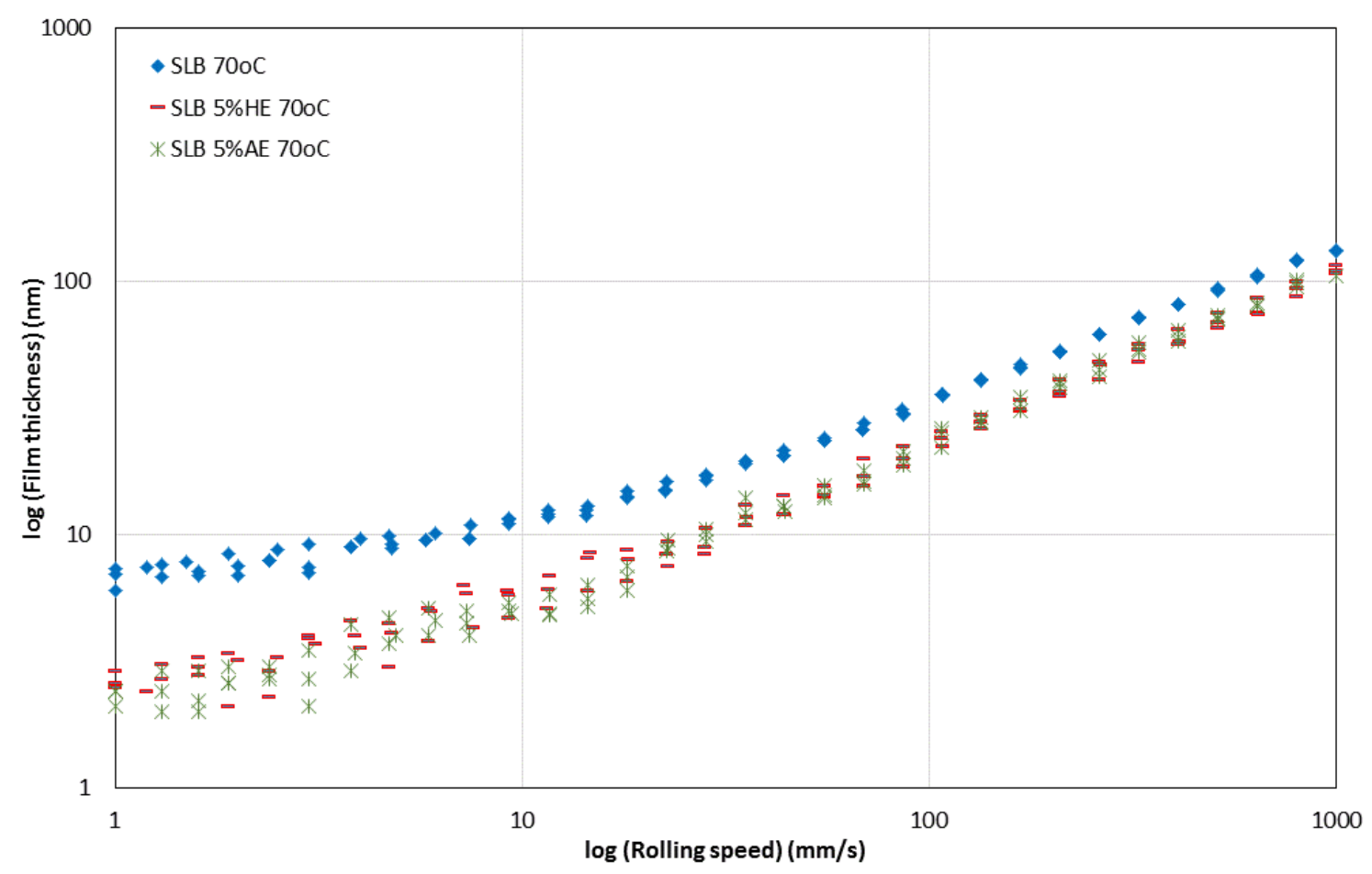

Figure 7. Effect of addition of ethanol to formulated oil SLB on film thickness at $70^{\circ} \mathrm{C}$. 


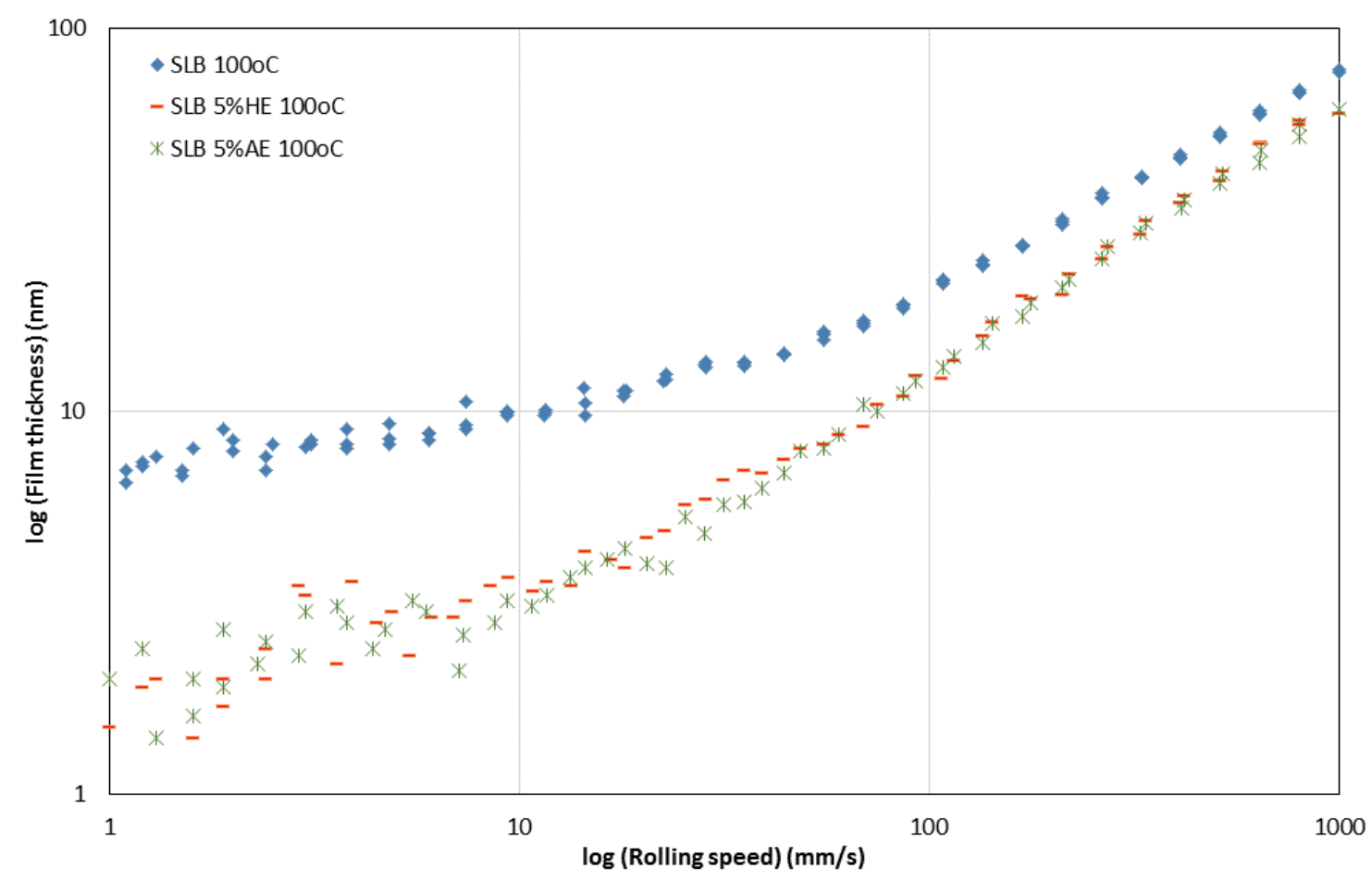

Figure 8. Effect of addition of ethanol to formulated oil SLB on film thickness at $100^{\circ} \mathrm{C}$. 


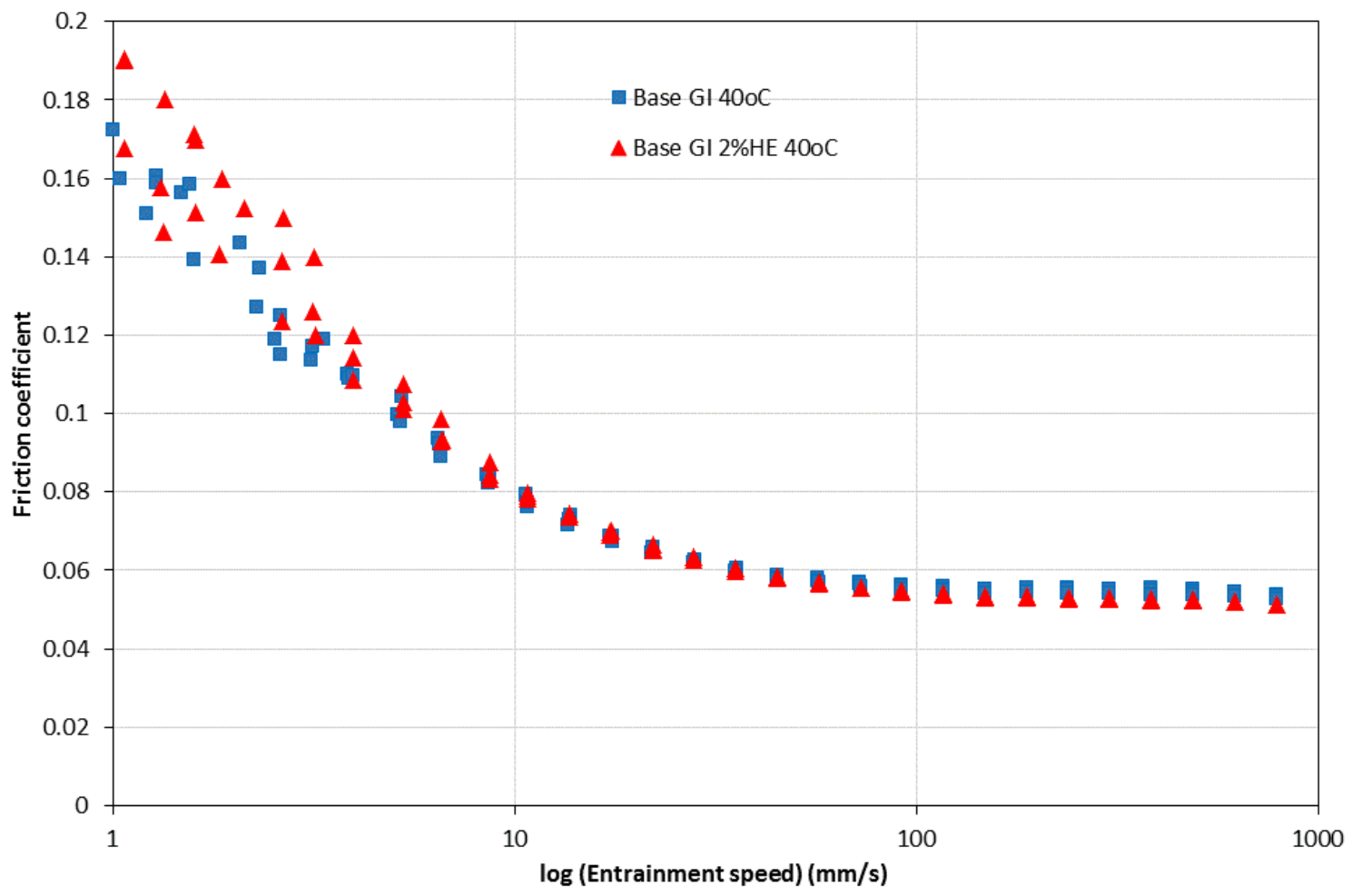

Figure 9. Effect of hydrated ethanol on Stribeck curves for Group I base oil, $40^{\circ} \mathrm{C}$. 


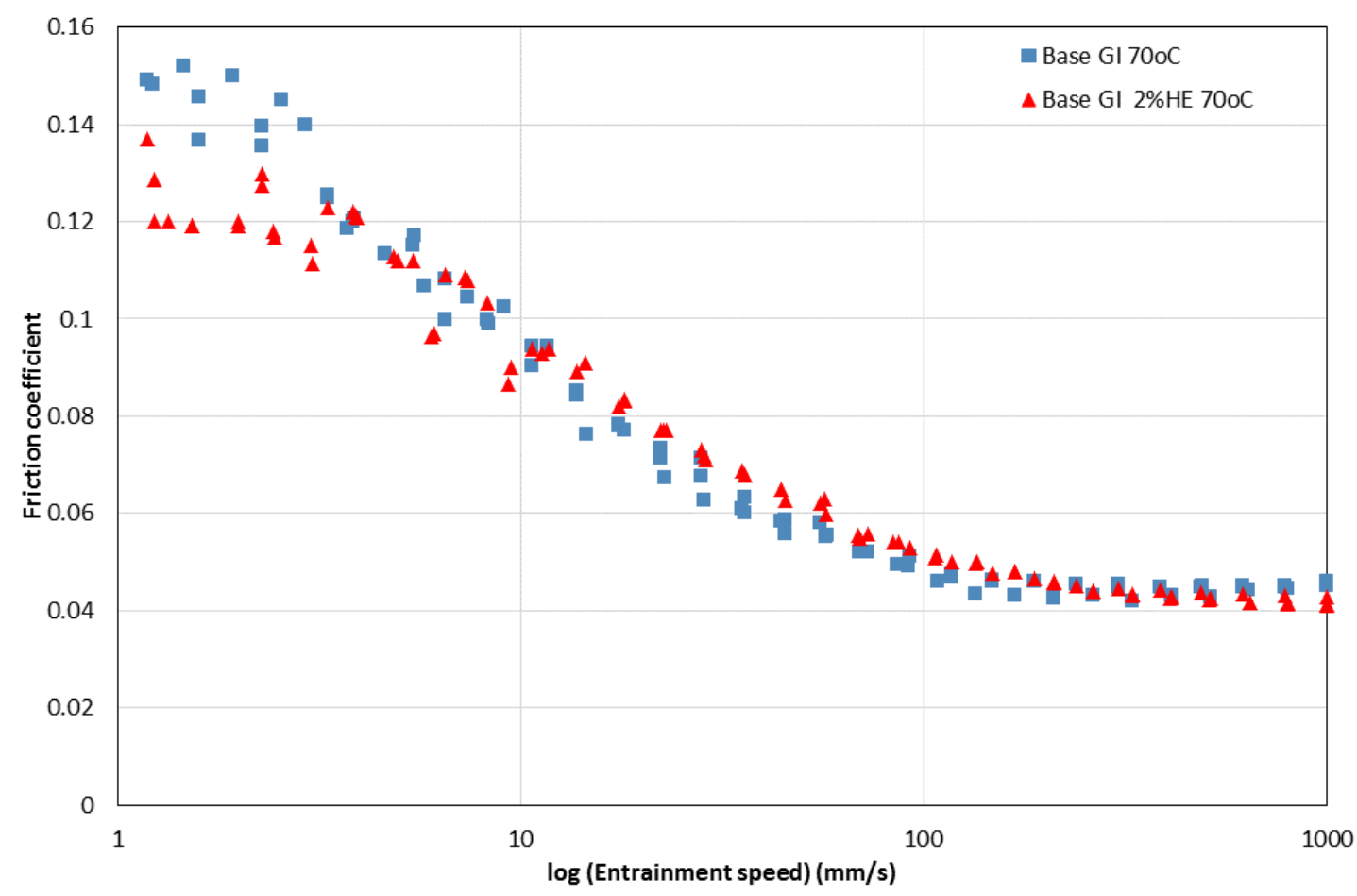

Figure 10. Effect of hydrated ethanol on Stribeck curves for Group I base oil, $70^{\circ} \mathrm{C}$. 


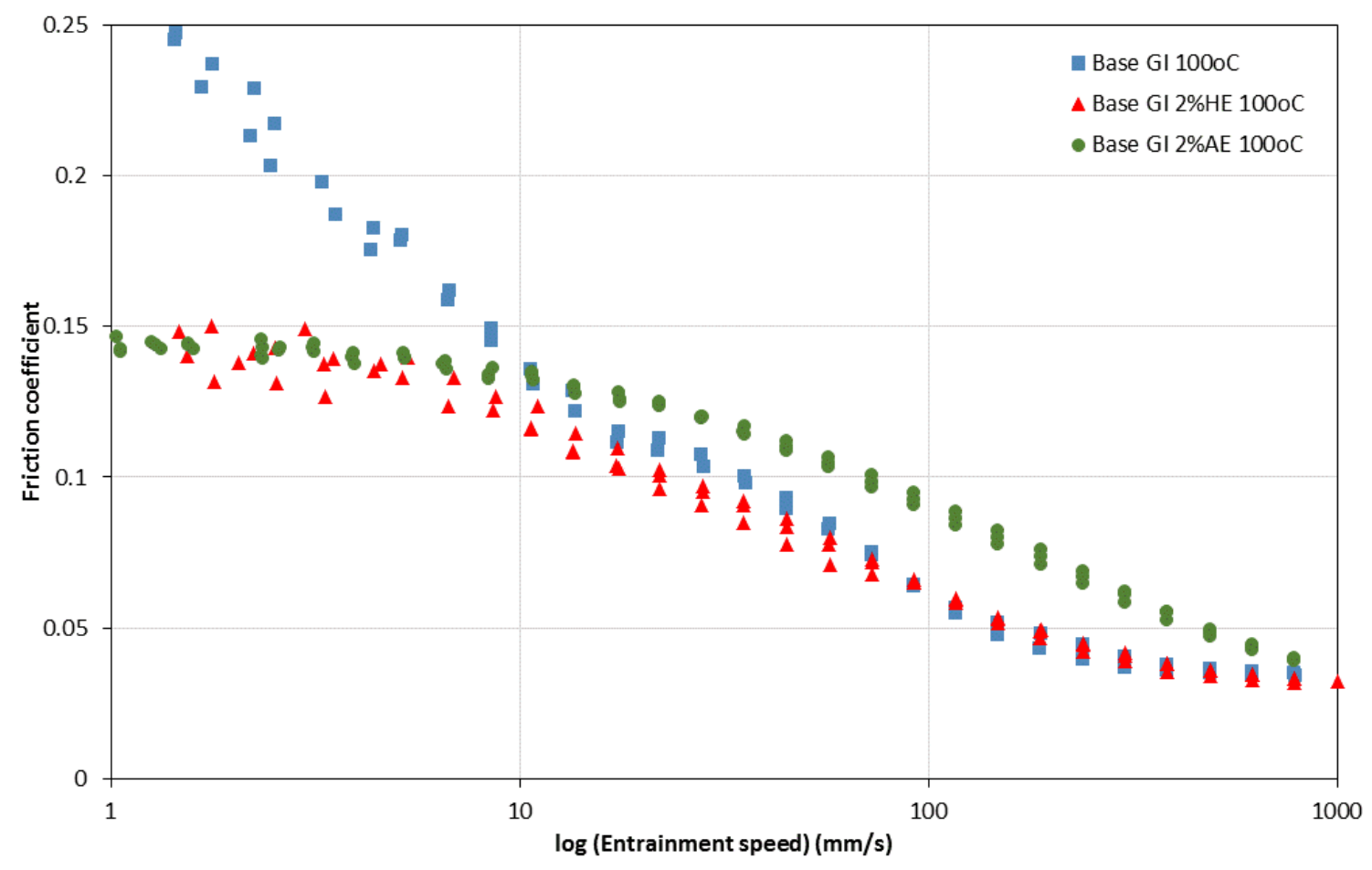

Figure 11. Effect of ethanol on Stribeck curves for Group I base oil, $100^{\circ} \mathrm{C}$. 


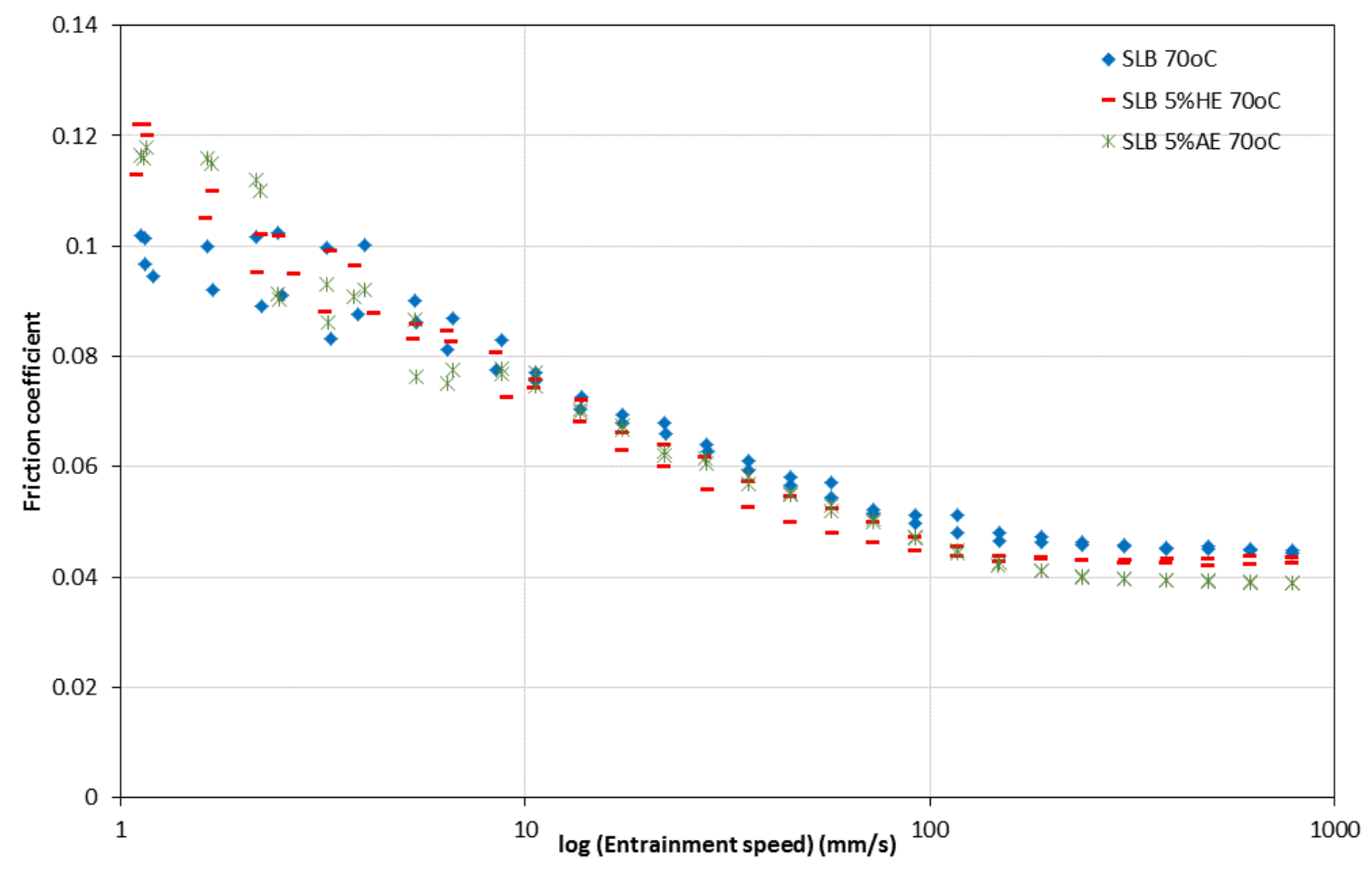

Figure 12. Effect of ethanol on Stribeck curves for the formulated oil SLB, $70^{\circ} \mathrm{C}$. 


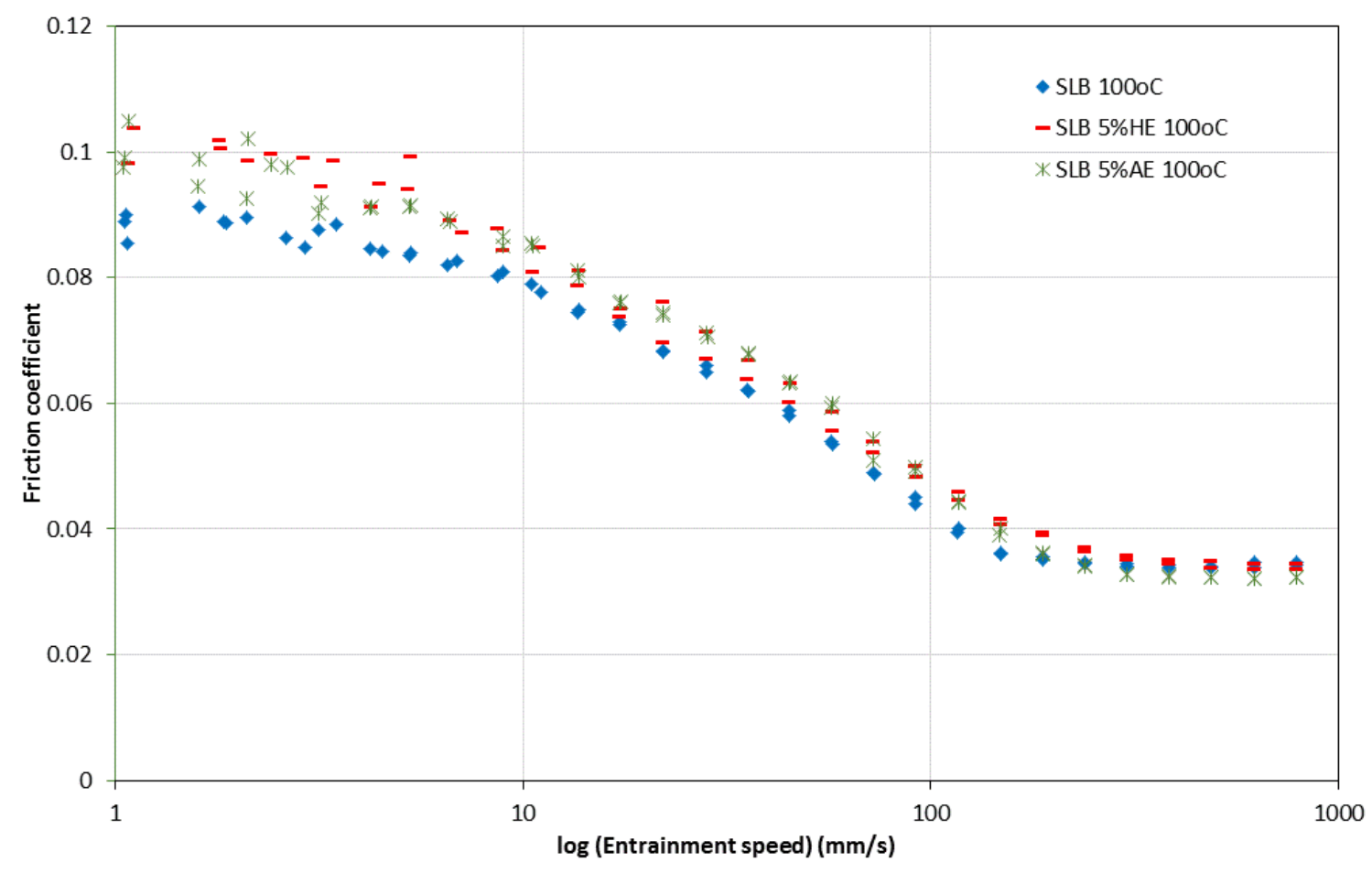

Figure 13. Effect of ethanol on Stribeck curves for the formulated oil SLB, $100^{\circ} \mathrm{C}$. 


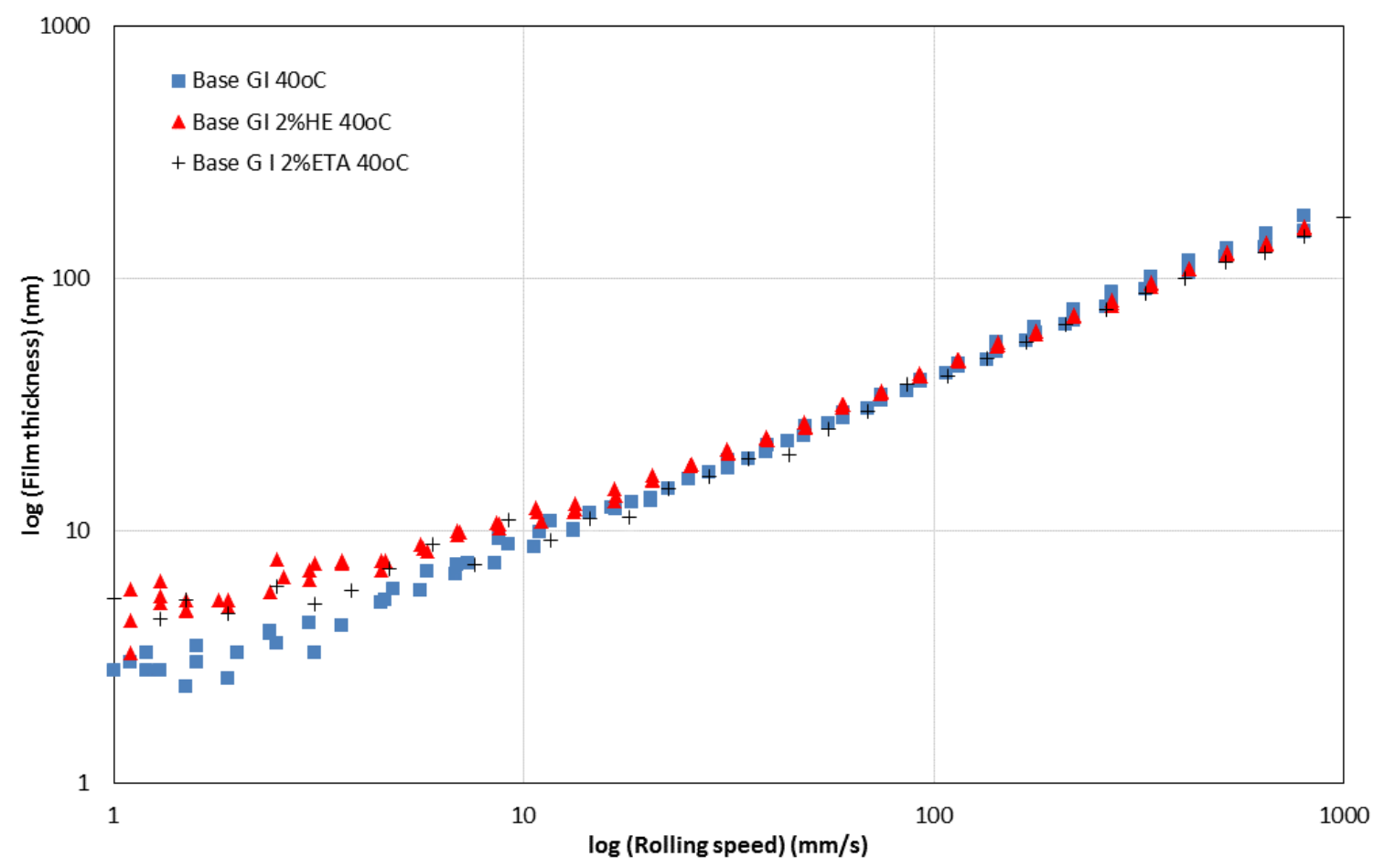

Figure 14. Effect of addition of ethanal (ETA) on film thickness for Group I base oil at $40^{\circ} \mathrm{C}$. 


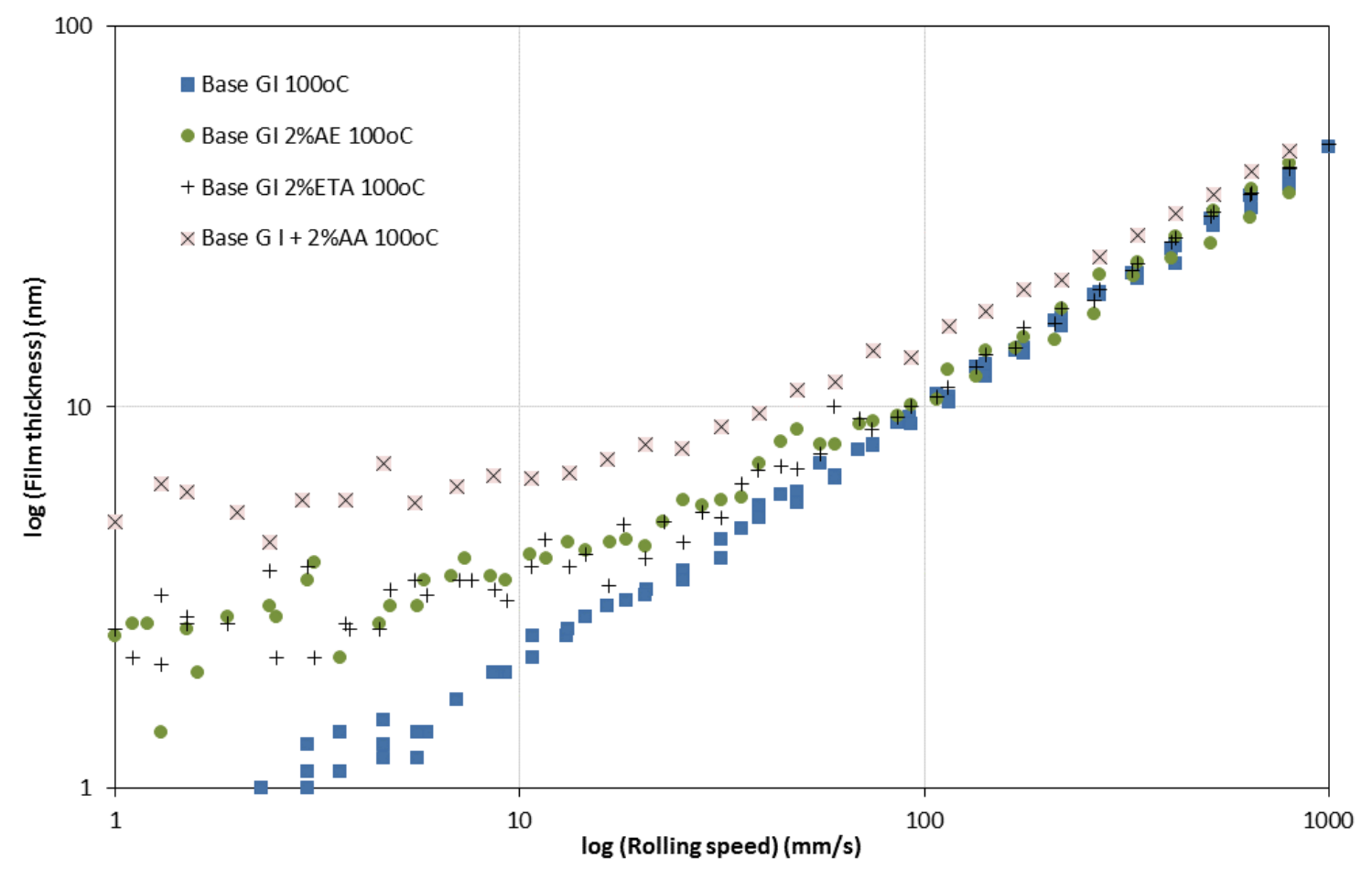

Figure 15. Effect of addition of acetic acid (AA) and ethanal (ETA) on film thickness for Group I base oil at $100^{\circ} \mathrm{C}$. 


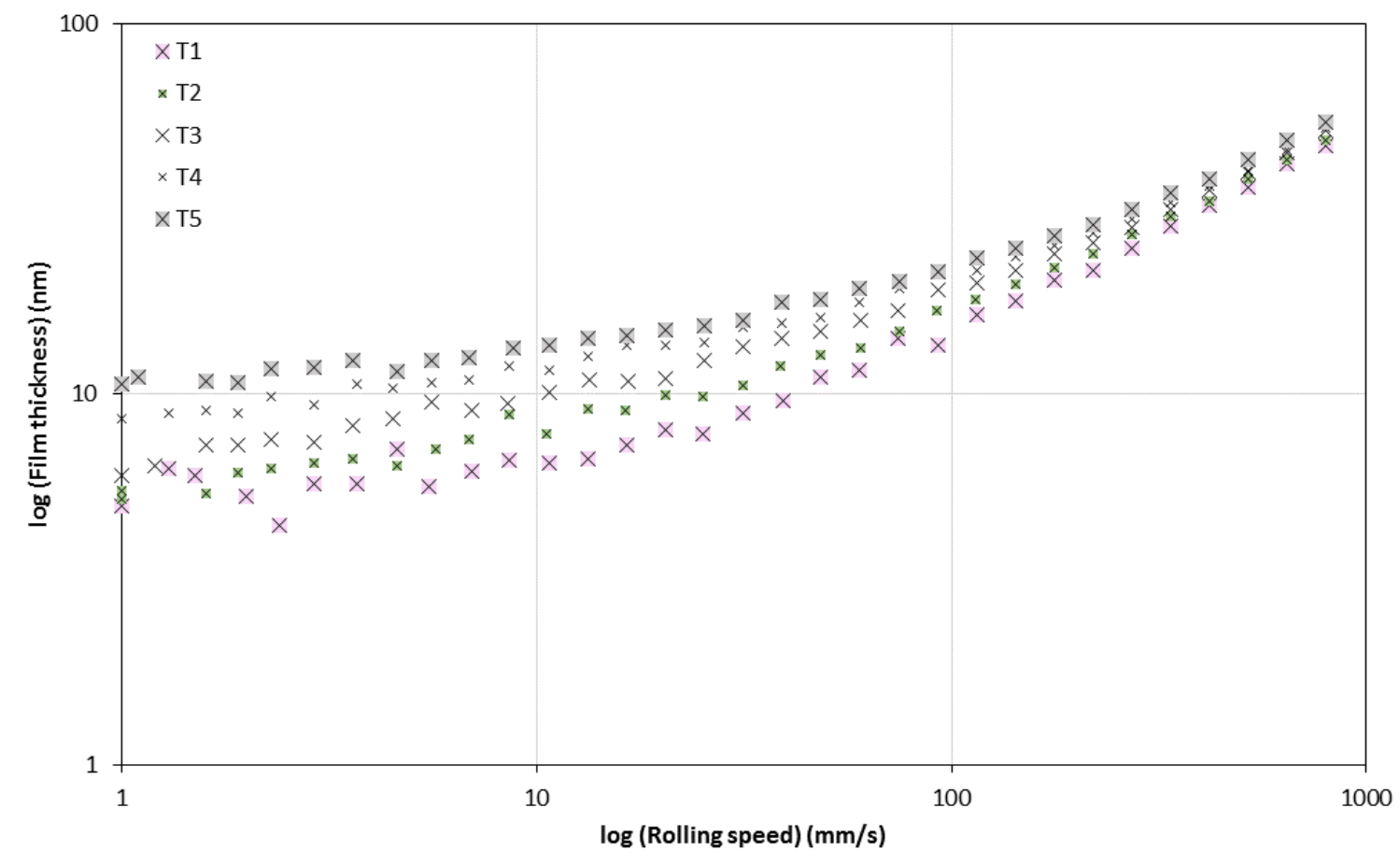

Figure 16. Five consecutive film thickness measurements for mixture of Group I base oil + acetic acid at $100^{\circ} \mathrm{C}$. 


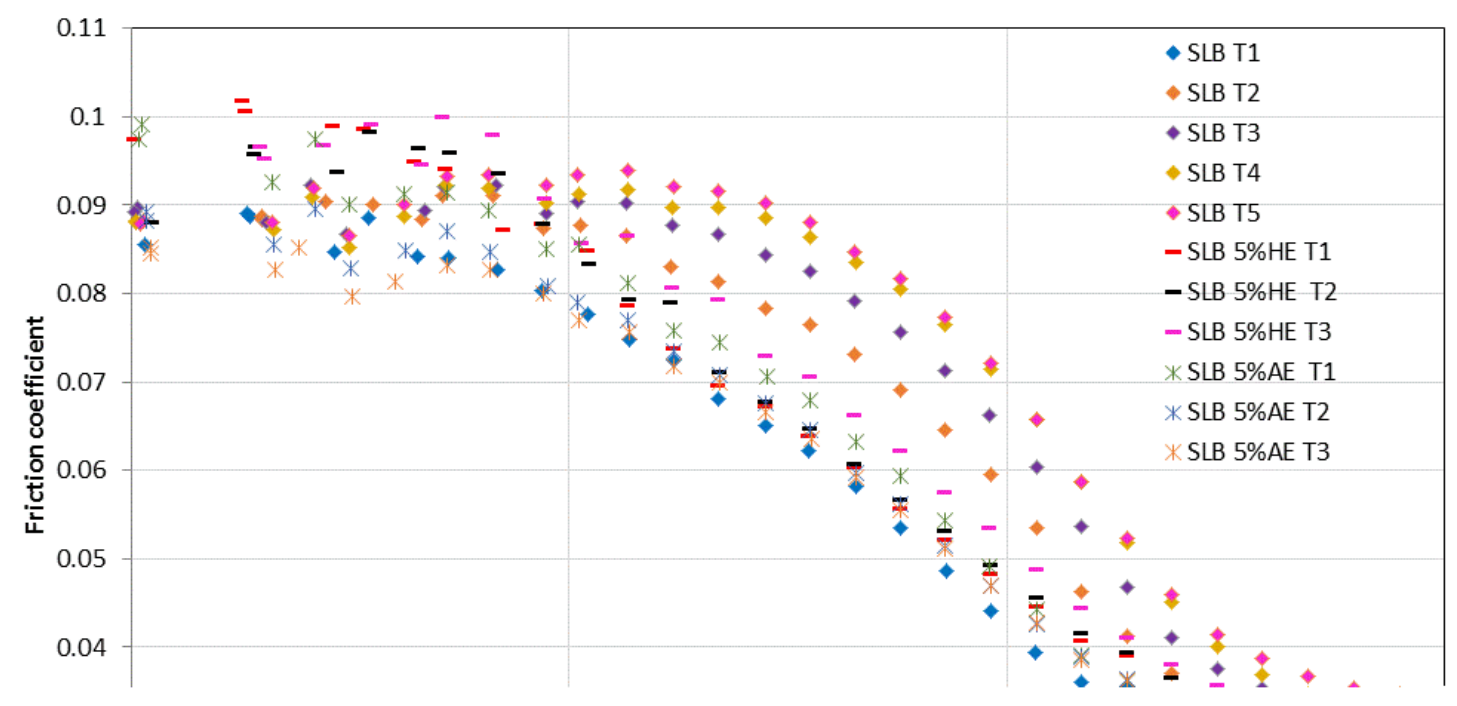

Figure 17. Effect of the addition of ethanol on consecutive Stribeck curves for the formulated oil SLB at $100^{\circ} \mathrm{C}$. 